\title{
Pedagogical content knowledge and preparation of high school physics teachers
}

\author{
Eugenia Etkina \\ Graduate School of Education, Rutgers University, New Brunswick, New Jersey 08904, USA
}

(Received 9 November 2009; published 31 August 2010)

\begin{abstract}
This paper contains a scholarly description of pedagogical practices of the Rutgers Physics/Physical Science Teacher Preparation program. The program focuses on three aspects of teacher preparation: knowledge of physics, knowledge of pedagogy, and knowledge of how to teach physics (pedagogical content knowledgePCK). The program has been in place for 7 years and has a steady production rate of an average of six teachers per year who remain in the profession. The main purpose of the paper is to provide information about a possible structure, organization, and individual elements of a program that prepares physics teachers. The philosophy of the program and the coursework can be implemented either in a physics department or in a school of education. The paper provides details about the program course work and teaching experiences and suggests ways to adapt it to other local conditions.
\end{abstract}

DOI: 10.1103/PhysRevSTPER.6.020110

PACS number(s): 01.40.J-, 01.40.gb, 01.85.+f

\section{WHAT SHOULD THE TEACHERS KNOW?}

\section{A. Complex nature of teacher knowledge}

Research in education demonstrates that the success of the current reform goals in K-12 science education depends on the preparation of teachers $[1,2]$. In addition to knowing the concepts and laws of physics and the methods of scientific inquiry (this knowledge is called knowledge of content), teachers should be able to create learning environments in which students can master the concepts and the processes of science. Teachers should know how people learn, how memory operates, and how a brain develops with age (this knowledge is called general pedagogical knowledge or the knowledge of how people learn). Most importantly, teachers of a specific subject should possess special understandings and abilities that integrate their knowledge of this subject's content and student learning of this content. This special knowledge, called pedagogical content knowledge (PCK), distinguishes the science knowledge of teachers from that of scientists. Pedagogical content knowledge, defined by Shulman as "the special amalgam of content and pedagogy that is uniquely the providence of teachers, their own special form of professional understanding..." [[3], p. 8], has become a key word in teacher preparation and assessment. Another important idea is that teaching science based on the methods advocated by current reforms is fundamentally different from how most teachers learned science themselves [4]; yet research indicates that teachers, unfortunately, tend to teach the way they have been taught $[5,6]$. The above arguments suggest that preparation of physics teachers should be a purposeful intellectual endeavor that needs to be carried out by professionals who possess strong expertise in the content area, can apply it to learning of physics and simultaneously have skills and experience in implementing the reformed way of teaching in a classroom.

\section{B. Three pillars of teacher knowledge: content knowledge, knowledge of how people learn and pedagogical content knowledge}

In the traditional path to becoming a teacher, preservice teachers are supposed to develop their content knowledge (knowledge of the discipline they will teach) and pedagogical knowledge (general knowledge of how people learn and how schools work). They learn the former while taking courses in the physics department. The latter knowledge is the domain of the schools of education. It includes the knowledge of psychology, general understandings of how people learn (for example, how memory works), how they work in groups, etc. However, in the past 20 years many teacher educators came to a conclusion that the most important aspect of teachers' practical knowledge, particularly for secondary teachers, is their pedagogical content knowledge $[7,8]$. Shulman $[3,9]$ describes pedagogical content knowledge (PCK) as the knowledge of subject matter for teaching. It includes knowledge of students' difficulties and prior conceptions in the domain, knowledge of domain representations and instructional strategies, and knowledge of domainspecific assessment methods (see Fig. 1) [10]). Others have since then elaborated on the construct $[11,12]$. Where and how can preservice teachers develop this type of knowledge?

Much has been written about the nature and development of PCK [e.g., [13-20]]. One of the main ideas is that PCK is a personal construct and each teacher develops their own PCK over the years of teaching. Although some disagree that teachers' PCK can be developed during teacher preparation [8], Grossman, Schoenfeld and Lee [21] argue that there are some aspects of PCK that can be formed during teacher preparation years. Specifically, programs can help preservice teachers develop their PCK in regard to their understanding of student ideas in the domain and how to build on students' existing knowledge (see, for example, the work of Jim Minstrell on facets of student reasoning [22]). Obviously teacher preparation can only do so much, and a substantial building of PCK will occur during the formative induction years (first 3 years) of teachers' professional development. The first 3 years feature the greatest changes to teachers' practice until it stabilizes around the fourth year of teaching [20].

Magnusson, Krajcik, and Borko [12] suggest five aspects of PCK that preservice secondary science teachers can begin to develop during their preparation. Described briefly, those are: orientation to teaching, knowledge of curricula, knowledge of student prior understanding and potential difficulties, knowledge of successful instructional strategies, and knowl- 


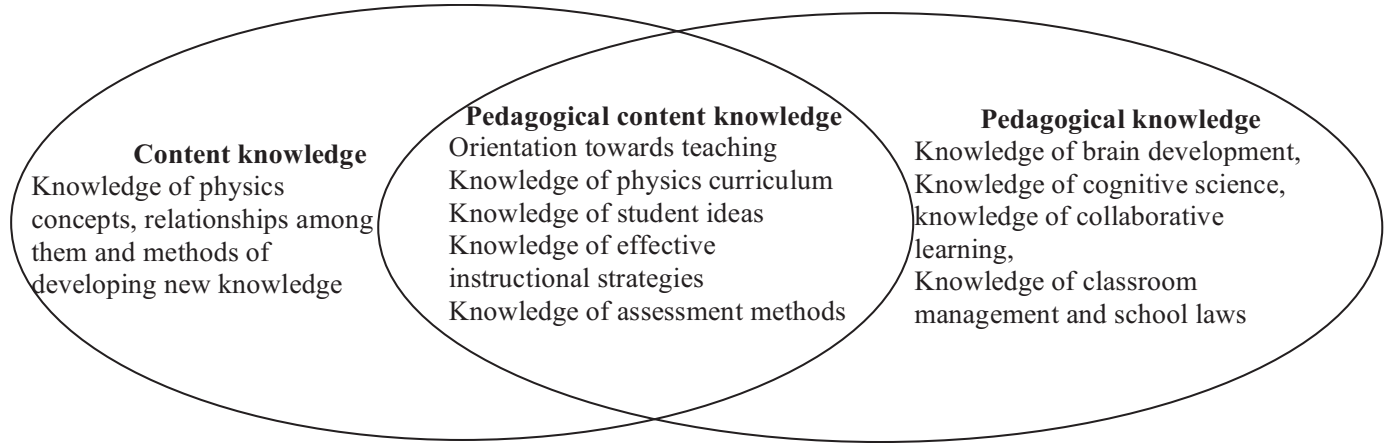

FIG. 1. The Structure of Physics Teacher Knowledge.

edge of assessment. Table I shows how the aspects of the model are related to physics teaching.

Three main points can be taken from the examples in the table:

(1) Deep content knowledge is a necessary condition for the development of PCK. If a teacher themselve does not understand the nuances of a concept, the deep relationships between this particular concept and other concepts, and the ways through which this concept was constructed by the physics community, then translating these nuances into student understanding is impossible. Therefore it is critical that future physics teachers are skilled in the content and processes of physics $[3,6,12]$.

(2) Understanding of the processes of learning is crucial for the development of the orientation toward teaching, assessment methods, understanding of the role of student ideas, etc. For example, the awareness of the complex nature of brain activity should affect how teachers deal with what is widely perceived as "student misconceptions" [29].

(3) PCK is highly domain specific; therefore, it is critical that future teachers develop teachers' PCK in the specific topics that they will be teaching. This is particularly relevant in the sciences; the different disciplines such as biology, physics, and earth science have distinct teaching methodologies, curricula, and instructional sequences [30]. Each subject has its own PCK. Several books are dedicated to science PCK, one of them being [20]. In physics many aspects of PCK are explicitly and implicitly addressed in [31-33].

\section{Course work to learn how to teach physics}

As mentioned above, in the traditional approach to teacher preparation, future teachers learn the content of the disciplines they will teach in the arts and science departments and the teaching methods in the schools of education. Studies of teacher preparation programs in schools of education find that most of them have one course that prepares future teachers to teach their subject. In science education, teachers of all sciences (biology, physics, chemistry, and earth science) enroll in the same course, i.e., "Materials and Methods in Secondary Science," which cannot prepare them for the instruction of all the complicated topics of their discipline. In their review of methods courses, Clift and Brady reported that few teacher preparation programs were "preparing to teach distinctly different areas of science, such as physics or biology" [[34], p. 322]. They suggested that more content-specific methods courses where students learn how to teach the subject of their specialization are necessary to prepare high quality teachers. Moreover, the undergraduate coursework in their respective science disciplines leaves future teachers with gaps in their content understanding [6] and does not seem to prepare future teachers to teach in ways that follow the recommendations of the National Science Education Standards. Many future teachers do not experience the reformed, interactive-engagement pedagogy while learning the content. Thus, there is a need for preservice teachers to reconceptualize the content when they enter teacher preparation programs, not only to become familiar with the aspects of PCK such as outlined above but also to experience how science learning happens in reformed environments.

\section{Physics specific clinical practice}

If one cannot learn physics by just listening and reading but needs to engage in the active process of knowledge construction, the same should apply to PCK; one can only acquire PCK by actively constructing it in the process of teaching (called clinical practice). Thus an opportunity to model good teaching with learners becomes equally important for teacher preparation [3,7]. This modeling can happen either in the courses where students learn physics, if physics learning is followed by reflection on how one learned, or in contentspecific methods courses. In these courses, preservice teachers first act as students learning a particular concept or procedure through a method that they are expected to use later when they start teaching; then later in the course they engage in microteaching. Microteaching is a technique where the preservice teachers teach their lessons and their peers act as high school students. Although it might seem that teaching a lesson to one's peers is not the same as teaching it to high school students, many elements of such practice are extremely useful: learning to plan the lesson, learning to choose the resources to achieve specific goals, learning to study research evidence on students' ideas, and finally learning to interact with "potential" students and revise the plan based on questions and comments that come up during the teaching of the lesson. Another way to engage future teachers in reformed teaching is for them to become Learning Assistants (Learning Assistants are talented undergraduate science majors with demonstrated interest in teaching; they 
TABLE I. Five aspects of PCK and their relationship to teaching physics.

\begin{tabular}{ccc}
\hline \hline $\begin{array}{c}\text { Aspect of } \\
\text { PCK }\end{array}$ & $\begin{array}{c}\text { How this relates to } \\
\text { teaching physics }\end{array}$ & Specific example from physics \\
\hline
\end{tabular}

Orientation to science teaching.

Knowledge of curricula.

Knowledge of students' prior understandings about and difficulties with key concepts and practices in science.
Beliefs regarding the role of students' prior

knowledge in their

learning, the purpose of problem solving, the roles of experiments in the classrooms, what motivates students in the classroom, etc.
For example, 3 teachers have the following beliefs about the purpose of problem solving in physics:

Teacher A: When students solve more textbook problems, students learn to apply physics principles and connect physics and math.

Teacher B: Students learn to reason like scientists; they need to learn to represent problem situations in multiple ways.

Thus students should learn to represent a particular situation in multiple ways without solving for anything.

For example when studying circular motion students are provided with the pictures of three roller coastersmoving on a flat surface, at the bottom of the loop and on the top (upside down). They need to draw motion and force diagrams for each coaster and write Newton's second law for the radial direction [23].

Teacher C: To be proficient problem solvers students need to use a clear sequence of steps that will help them acquire the habit of drawing a picture, representing the situation, evaluating their answer, etc [24].

One needs to understand the ideas of impulse and momentum in order to construct a microscopic model of gas pressure [25].

to build the understanding

of a new concept or skill

on what she or he already knows.

Knowledge of students' preinstruction ideas when they are constructing a new concept.

Knowledge of difficulties students may have interpreting physics language that is different from everyday language.

Knowledge of multiple methods or specific activity sequences that make student learning more successful and an ability to choose the most productive strategy or modify a strategy for a particular group of students or an individual.
Productive ideas: Conservation and transfer of money can be related to such conserved quantities as mass, momentum, and energy.

Language: Heat in everyday language is treated as a noun-a quantity of stuff-whereas in physics, heating is an active process involving the transfer of thermal energy. Also, force is often treated as an entity (an object has a weight of $50 \mathrm{~N}$ ) as opposed to an interaction between two objects [26].

For example, when students learn Newton's laws, it is helpful to label any force with two subscripts indicating two interacting objects [25]; when students learn about electric current and potential difference,

it is useful to know that an analogy between a battery and a water pump might not be clear for the students as many do not understand how pumps work [27]. are hired to facilitate interactive, student-centered approaches in large-scale introductory science courses after they themselves passed this course [35]) or laboratory or recitation instructors in the physics courses that follow reformed curricula. In most teacher preparation programs, students have to do student teaching in which they assume some of the responsibilities of the classroom teachers for a limited period of time. This is another opportunity for them to prac- tice this new way of teaching. For both types of activities (microteaching with their peers as students and teaching "real" students) to contribute to the development of PCK, physics teacher educators need to constantly provide help and feedback to the future teachers and then slowly "fade" that feedback (that is, reduce its extent) as the future teachers become more and more skilled. Therefore learning and mastering PCK resembles "cognitive apprenticeship"—a process 
TABLE I. (Continued.)

\begin{tabular}{|c|c|c|}
\hline $\begin{array}{l}\text { Aspect of } \\
\text { PCK }\end{array}$ & $\begin{array}{l}\text { How this relates to } \\
\text { teaching physics }\end{array}$ & Specific example from physics \\
\hline $\begin{array}{l}\text { Knowledge of what to } \\
\text { assess } \\
\text { and specific strategies to } \\
\text { assess students' } \\
\text { understandings of key } \\
\text { concepts and practices. }\end{array}$ & $\begin{array}{l}\text { Knowledge of ways to assess student } \\
\text { conceptual understanding and problem } \\
\text { solving and general scientific abilities; } \\
\text { knowledge of how to help students } \\
\text { self-assess their work and to engage } \\
\text { in a meaningful reflection. }\end{array}$ & $\begin{array}{l}\text { For example, physics "Jeopardy" problems in which a } \\
\text { student has to describe a situation that matches a given } \\
\text { equation are an effective way to assess whether students } \\
\text { understand the meanings of the symbols in mathematical } \\
\text { equations that they use to describe physical processes and } \\
\text { to solve problems [28]. An example of a Jeopardy } \\
\text { problem is: A solution to a problem is described } \\
\text { mathematically as } 0.020 \mathrm{~N}=(0.020 \mathrm{~A})(0.10 \mathrm{~T}) L(0.50) \text {. } \\
\text { Draw a picture of a possible situation described by the } \\
\text { equation and write the problem description in words. }\end{array}$ \\
\hline
\end{tabular}

of acquiring a cognitive skill with slowly fading coaching and scaffolding [36]. Scaffolding is a temporary support provided by the instructor to assist learners; it can be done through questions, prompts, suggestions, etc. [37,38]. The support is then gradually withdrawn, so that the learners assume more responsibility and eventually become independent.

In this paper, I describe a graduate program for preparing physics teachers, focusing mostly on how it helps them build physics knowledge and physics PCK through cognitive apprenticeship (there will be fewer details on how the program develops future teachers' general pedagogical knowledge). Although this particular program is housed in the School of Education, similar course work and especially the clinical practice can happen in a physics department.

\section{BUILDING A PROGRAM TO HELP FUTURE TEACHERS LEARN WHAT THEY NEED}

\section{A. Cognitive apprenticeship and PCK}

Cognitive apprenticeship is in many ways similar to traditional apprenticeships used in preparation of artists, musicians, tailors, etc. At first, the apprentices observe the expert as he or she models desired practices. Then the apprentices attempt the practice and the expert provides feedback (on past performance), coaching (advice and examples for future performance) and scaffolding (support during performance). The expert slowly removes scaffolding and finally provides apprentices with opportunities for independent practice. However, cognitive apprenticeship differs from regular apprenticeships because some of the processes and skills used by the expert are mental and thus cannot be observed directly. Thus it is necessary to make the process explicit and "visible" for the apprentices [39].

A similar approach is used in science research groups while training graduate students to become scientists. It is not enough for the students to simply observe other scientists doing their work; they need to understand the invisible thinking processes behind the scenes. At the same time, they need constant feedback when they start engaging in the practice themselves. And since the practice is very complex, multiple exposures in different contexts are necessary for a graduate student to become a scientist. The same is true for a teacher.
The craft is complex and invisible, often subconscious for the teacher herself. Thus to learn to be a high-quality teacher, the person needs multiple exposures in different contexts and the explicit effort of an expert teacher to make her thinking and her basis for decision-making in the classroom visible to the novices. In addition, preservice teachers need to have opportunities to practice the skills of listening to the students, changing their plans depending on what students say, responding to specific student comments, planning what questions to ask, etc., first in "sheltered environments" and then gradually moving to independent teaching. Table II summarizes the opportunities a preservice physics teacher preparation program needs to provide for its students so they acquire PCK through cognitive apprenticeship.

\section{B. Theory into practice: rutgers physics teacher preparation program}

In this Sec. I will describe the physical science teacher preparation program at Rutgers, The State University of New Jersey, which is designed to provide preservice physics teachers with all of the opportunities described in Table II. As with every teacher preparation program, this program is tailored to the specific certification requirements of the state. In the state of $\mathrm{NJ}$ all high school teachers are required to have a major in the subject they are teaching or a 30 -credit coherent sequence in that subject (with 12 credits at the 300400 level) and pass the appropriate licensure exam(s). According to state requirements, there are separate certifications for physics teachers, chemistry teachers, and physical science teachers. A physics teacher needs to satisfy the requirements described above; a physical science teacher needs to be eligible for certification in either physics or chemistry according to the requirements for all subjects and then have 15 credits in the other subject. In addition, every certification program in the state has to show that its graduates satisfy NJ Professional Teaching Standards. If a teacher is certified to teach one subject, they can obtain another certification after satisfying the major requirements in this subject and passing the relevant licensure exam(s).

Because of the above, and because of the research done by the Holmes group [41] on the importance of strong undergraduate background for teachers, the program at Rutgers 
TABLE II. Elements of the teacher preparation program.

\begin{tabular}{ccc}
\hline \hline $\begin{array}{c}\text { What preservice physics } \\
\text { teachers should learn }\end{array}$ & $\begin{array}{c}\text { The program provides opportunities for a } \\
\text { preservice teacher to }\end{array}$ & How this relates to PCK \\
\hline
\end{tabular}

Physics content and processes through which knowledge is acquired.

How their students learn physics and how to assess their learning.
1) be a student in a classroom where physics (both content and the processes) is taught in ways that are consistent with the knowledge of "how people learn" [40],

2) engage in this way of teaching, and

3) reflect on their own learning of physics and on the learning of others.
Orientation to science teaching.

Knowledge of curricula.
1) read research literature on student learning;

2) observe and interview students learning physics,

3) reflect on classroom observations,

4) study different curriculum materials, and

5) interpret student work.
How to actually be a teacher in a physics classroom, how to set goals for student learning, how to help the students achieve the goals, and how to assess whether students achieved the goals.
1) engage in teaching or co-teaching in environments that mirror the environments that we want them to create later (at first, without planning or assessment), 2) then add planning and assessment but with scaffolding and coaching, and finally,

3) engage in independent teaching that involves planning and assessment.
Knowledge of students' ideas and difficulties. Knowledge of instructional strategies. Knowledge of assessment methods.

All of the above. is a graduate level program. The Rutgers Graduate School of Education (GSE) has had a master's program in teacher preparation for the last 15 years; however before 2001, there was no special preparation program for physical science teachers. All science teachers were prepared together and based on their undergraduate majors they were certified to teach either biology or physical science (there was no special certification in physics in $\mathrm{NJ}$ at that time, there was only physical science). There were no content-specific methods courses where preservice teachers learned physics PCK. Before 2001 there were only 0 to 2 physical science teachers certified per year.

In 2001, the science program was reformed. It was split into two: life science and physics or physical science (by that time NJ had three separate certifications-for physical science, for physics only, and for chemistry only; Rutgers chose not to certify teachers in straight chemistry due to the absence of a chemistry education expert in the Graduate School of Education). Both physics or physical science and life science programs are offered as a 5-year program or a postbaccalaureate program. This paper only focuses on the physics or physical science programs. Appendix A shows the paths one can follow to get an Ed.M. degree and a physics certification at the Rutgers Graduate School of Education (GSE) and the details of different programs.

A short explanation might help the reader understand the difference between physical science and physics programs. The physical science program leads to a certificate in physical science. The prerequisite for admission is a physics major +15 chemistry credits or a chemistry major +15 physics credits. Students who receive physical science certifica- tion can be hired to teach physical science in middle schools and high schools (that involves a mix of physics and chemistry), and can also teach physics and chemistry. Students who receive physics certification (for which a physics major is a prerequisite) can be hired to teach high school physics only. Having the physical science certification not only allows physics majors to teach more subjects, but also allows chemistry majors to enroll in the program if they have a sufficient number of physics credits. Combining physics and physical science programs into one program is natural thing to do as in high school physical science, and even in chemistry, almost $50 \%$ of the content belongs to both chemistry and physics (gas laws, thermodynamics, atomic, and nuclear structure, etc.). However, due to the nature of the program, it attracts mostly physics majors. (In the last 2 years only one chemistry major went through the program; her teaching load now consists of one chemistry course, one physics course, and two physical science courses). What is important here is that the content of the programs once a students is enrolled is identical, the same is true for the 5-year and the postbaccalaureate programs.

The goals of both the 5-year and the postbaccalaureate programs stated in the program mission are to prepare teachers of physics or physical science who are knowledgeable in the content and processes of physics, who can engage students in active learning of physics that resembles scientific inquiry, and who can assess student learning in ways that improve learning.

To address these goals, the new program has multiple ways through which it prepares preservice teachers to teach physics or physical science. These can be split into three 
TABLE III. Coursework and clinical practice.

\begin{tabular}{|c|c|c|c|c|}
\hline Year/semester & General Education & Physics PCK and physics & As a student & As a teacher \\
\hline 1/Spring & & $\begin{array}{l}\text { 1. Teaching physical } \\
\text { science } \\
\text { 2. Technology in science } \\
\text { education }\end{array}$ & $\begin{array}{l}\text { Plan multiple } \\
\text { lessons and one } \\
\text { whole unit, } \\
\text { teach a lesson } \\
\text { in class (as part of } \\
\text { a 2-student team). } \\
\text { Observe } 30 \text { h of HS } \\
\text { lessons (teach a lesson or two), } \\
\text { reflect on experiences, conduct } \\
\text { interviews with students. }\end{array}$ & \\
\hline 1/Summer & $\begin{array}{l}\text { 1. Assessment and } \\
\text { measurement } \\
\text { for teachers }(2 \text { credits })\end{array}$ & $\begin{array}{l}\text { 1. Research internship } \\
\text { in X-ray astrophysics }\end{array}$ & $\begin{array}{l}\text { Observe HS students } \\
\text { learning physics, } \\
\text { astrophysics, and X-ray } \\
\text { research in a } \\
\text { summer program. }\end{array}$ & $\begin{array}{l}\text { Teach sections in } \\
\text { introductory physics } \\
\text { summer courses } \\
\text { (full responsibility). }\end{array}$ \\
\hline 2/Fall & $\begin{array}{l}\text { 1. Classroom } \\
\text { management ( } 1 \text { credit) }\end{array}$ & $\begin{array}{l}\text { 1. Teaching internship } \\
\text { seminar for } \\
\text { physics students } \\
\text { 2. Teaching internship } \\
(9 \text { credits })\end{array}$ & $\begin{array}{l}\text { 1. Observe high school } \\
\text { physics instruction for } \\
2 \text { weeks, reflect on } \\
\text { teaching experiences } \\
\text { during the rest of the } \\
\text { semester, write lesson } \\
\text { and unit plans, tests. }\end{array}$ & $\begin{array}{l}\text { 2. Gradually assume } \\
\text { individual responsibilities } \\
\text { of a high school } \\
\text { physics teacher. } \\
\text { Plan, implement, and } \\
\text { assess lessons. } \\
\text { Plan, implement, and } \\
\text { assess one unit. }\end{array}$ \\
\hline 2/Spring & 1. Ethics & $\begin{array}{l}\text { 1. Multiple representations } \\
\text { in physical science } \\
\text { 2. Upper level } \\
\text { physics elective }\end{array}$ & $\begin{array}{l}\text { Plan multiple lessons } \\
\text { and one whole unit; } \\
\text { teach a lesson. }\end{array}$ & $\begin{array}{l}\text { Work as an instructor in } \\
\text { reformed recitations or } \\
\text { laboratories. }\end{array}$ \\
\hline After graduation & $\begin{array}{l}\text { Participate in web- } \\
\text { meetings twice } \\
\text { participate in pro }\end{array}$ & $\begin{array}{l}\text { ssed discussions, attend } \\
\text { month at the GSE, } \\
\text { ssional development. }\end{array}$ & $\begin{array}{c}\text { Work as a high school phys } \\
\text { teacher and reflect }\end{array}$ & $\begin{array}{l}\text { cs or physical science } \\
\text { experiences. }\end{array}$ \\
\hline
\end{tabular}

different categories: strengthening the physics content knowledge, preparing to teach physics or physical science, and practicing new ways of teaching in multiple environments (clinical practice). In addition the program builds a learning community of teacher candidates as they take courses in cohorts and continuously interact with each other during the two years of the program. What is extremely important here is that the Rutgers program does not end when preservice teachers graduate and become high school physics teachers. There is an infrastructure in place to help graduates continue to interact with program faculty and each other (maintaining and strengthening the community of all pro- gram graduates) and participate in a continuous professional development program.

Table III shows the structure of the program for the postbaccalaureate students. The students in the program take general education courses with other preservice teachers in the GSE; physics PCK courses and clinical practice are arranged so that the physics or physical science students are separate (in the technology course $50 \%$ of the work is with the preservice life science teachers). All courses are 3-credit courses unless otherwise noted.

Table III shows that there are six physics-specific teaching methods courses that students take. Since it is impossible to 
describe all of them in this paper, I focus on the similar elements in the structure of the courses in the following section and then describe three of them in detail in Sec. IV. The syllabi of all of them and examples of class assignments and student work are available in Appendix D at XX (URL will be provided by the PhyRev ST PER). The choice of these three is based on the premise that they can be taught in a physics department.

\section{Rutgers program and PCK courses}

All PCK courses have a similar structure. The theoretical foundation for the structure is cognitive apprenticeship. The content of the courses is a combination of physics (content and process) that teacher candidates will be teaching in a high school; knowledge of how to engage students in the learning of physics (science and physics education research) and how to plan and implement this instruction (science education and teacher preparation). Students attend a 3-h class meeting once a week. In the first half of the semester they learn physics and PCK through interactive-engagement methods (students who learn through these methods investigate physics phenomena with the guidance of instructor and devise and construct their own ideas as opposed to being told about them, for more information see Refs. [40,42]). Then they work individually at home reflecting on the class experience, studying additional resources, and writing either about how a particular physics idea was constructed by physicists or planning how they will teach a particular idea in a high school classroom. In addition, they work in groups on a comprehensive project that involves planning a unit of instruction and microteaching a lesson. The groups have two to three students. Each semester each student works with different partners, thus by the end of the program each student establishes working relationships with other students in the same cohort. In the second half of the semester all class meetings turn into lessons taught by the students. The assessment for the course is done multiple times through the feedback on weekly written homework and student projects, weekly class quizzes, and the final exam (in "Teaching Physical Science" and "Multiple Representations in Physical Science" courses). Students have an opportunity to improve their work as many times as needed to match the desired quality (usually the number of revisions ranges from 4 at the beginning of the semester to 1 at the end). Although the instructor gives formal grades at the end, they are often very high since all students redo and improve their work multiple times to meet course standards. Table IV provides the details for the courses and relates them to the elements of cognitive apprenticeship. Due to the nature of the assessment in the PCK courses and the intense work by the instructor with student groups preparing their lessons for microteaching, PCK classes cannot have large enrollment. Classes between 15 and 17 students are manageable.

Examples of Quiz questions in different courses show different foci and different levels of PCK sophistication (an example of a student's response to the quiz questions is in Appendix D, p. 35):

"Development of Ideas in Physical Science;" Week 7 Quiz question 2:

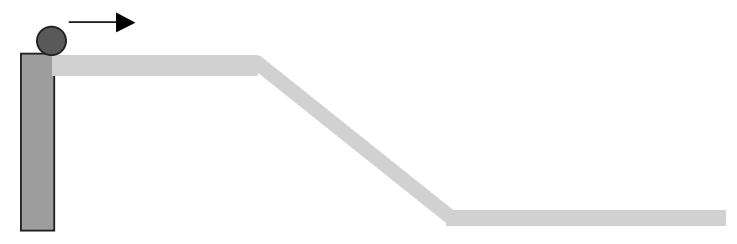

FIG. 2. Ball on track.

In his book Horologium Oscillatorium published in 1673, Christiaan Huygens described his method of controlling clocks with a pendulum. In this book one can find the following statement: "If a simple pendulum swings with its greatest lateral oscillation, that is, if it descends through the whole quadrant of a circle, when it comes to the lowest point of the circumference, it stretches the string with three times as great a force as it would if it were simply suspended by it." What should Huygens have known to be able to make this statement? Explain how he came up with the number 3 for the problem. Draw a picture, a free body diagram, and an energy bar chart if necessary.

Teaching Physical Science Quiz Week 3 (complete Quiz, the first assignment is taken from the book "Five Easy Lessons" by R. Knight)

(1) Draw position, velocity and acceleration vs time graphs for the ball that is moving as shown in Figure 2.

Place the graphs under each other so the reading on the time axis matches the clock readings when the ball passes different sections of the track.

(2) Draw one possible graph that a confused student would draw and explain why they would draw it.

Multiple Representations in Physical Science, Week 4, Question 1

A student says: "I do not understand: what is the difference between $\vec{E}$ and $V$ ? Why do we need both?"

(a) How do you respond to these questions for yourself?

(b) What would you do in class when a student asks these two questions?

\section{Nature of science foundation of PCK courses}

Although preservice teachers have (or are finishing) an undergraduate degree in the discipline, many learned the subject through traditional lecture-based instruction and not through the methods that they will need to use when they themselves teach. (However, this is changing now that some of the Rutgers introductory courses have been reformed in collaboration with the GSE.) Therefore, in all physics PCK courses, preservice teachers re-examine physics ideas via the methods that they can later use with their students. The main focus is on how to engage students in the active construction of their own ideas [42]. In particular, the program uses the framework of the Investigative Science Learning Environment (ISLE) [29]. ISLE is a comprehensive physics learning system created for introductory physics courses (used in college and high school) that replicates some of the processes

\footnotetext{
${ }^{1}$ The text of the statement can be found W.F. Magie, A Source Book in Physics (McGraw-Hill, New York, 1935), p. 30.
} 
TABLE IV. Repeated elements of physics PCK courses.

Course week

Weeks 1-7: Instructor models good teaching practices and preservice teachers reflect.

In-class work

Part 1: Preservice teachers act as students and participate in physics lessons that are conducted in an interactive, inquiryoriented manner; they work in groups on questions and problems and present their solutions on white boards.

Part 2: Preservice teachers act as teachers reflecting on the learning that happened in class and the actions of the instructor, analyzing them from the PCK point of view. Part 3: Preservice teachers act both as students and teachers by responding to the written formative assessment questions based on the content of the material and simultaneously on the responses given by high school students learning the same material. Even though students act as teachers reflecting on their learning and on the content of materials or quizzes, they do not lead the lessons.

Part 1: A group of preservice teachers teaches a 2-h lesson to the class; the rest act as students. The instructor focuses "teacher" attention on student responses and asks them to "rewind" the lesson if they did not hear or respond to the comments or questions.

Part 2: All students act as teachers. They reflect on the details of the lesson and discuss possible improvements.

Out-of-class work

Weeks 8-14: Preservice

teachers engage in with immediate feedback from the instructor and reflect on their experience.
Oral exam in which preservice teachers answer questions related to teaching specific physics topics, solve problems, and show interesting physics applications that would motivate their high school students to learn physics.
Both parts 1 and 2 continue from above. Part 3: Students work together preparing for the final oral exam.
Week 15 in multiple ways; multiple representations become the tools that they use to analyze physical phenomena and develop models. Many activities that students perform after they construct an idea require them to represent a physical process in different ways-sketches, diagrams, graphs, data tables, and mathematical equations-without solving for anything [see examples in (25)]. In the laboratories students design their own experiments without a cookbook recipe but with the help of questions that focus on the process of scientific reasoning $[43,44]$. In summary, the features of ISLE are closely matched with the guided inquiry-style teaching that the National Science Education Standards [1] and especially NJ state standards [45] encourage teachers to employ.

\section{E. Rutgers program and clinical practice}

The clinical practice is also organized on the principles of cognitive apprenticeship. Students observe and reflect on the lessons conducted by the program coordinator in the courses 
described above. They plan and implement their own "high school" lessons in those courses under close supervision and immediate feedback of the program coordinator. The also spend 10 half-days in high schools observing physics lessons and interacting with students during the second semester in the program. In addition for the first two semesters, preservice teachers work as instructors (either for laboratories or problem-solving sessions) in reformed physics courses similar to what physics graduate students would do. One can say that they are TAs except their teaching load is usually limited to one laboratory and/or one problem-solving session per week (which is about 2-3 contact hours, plus office hours, grading of homework or exams, and attendance at training meetings). The preservice teachers are fully and individually responsible for the learning of introductory physics students in the sections they teach. However, they do not plan their own recitations and do not design laboratory materials or write course exams. These plans and materials are provided for the preservice teachers by the course coordinator. Thus their teaching in the course is a very simplified and sheltered version of high school teaching where a teacher writes lesson plans, assembles equipment, writes tests, assigns course grades, etc. Preservice teachers' major responsibility is to implement instruction in a reformed atmosphere and reflect on what happened in class. This is possible as the physics course in which they teach is ISLE-based [29].

In problem-solving sessions undergraduate students work in groups on the assigned problem and then present their results to the class on a whiteboard and in laboratories they design their own experiments. The learning environment matches the national science standards and NJ state science standards and provides preservice teachers with an opportunity to practice teaching in ways they are expected to teach in a high school. The preservice teachers also have an opportunity to observe student responses and growth in such an environment. The instructor in that physics course is a physics education research (PER) expert who is deeply committed to working with preservice teachers.

In the second semester, preservice teachers spend 3 $\mathrm{h}$ /week for 10 weeks in local high schools observing high school physics lessons and reflecting on their observations (it is a part of the GSE structure for all teacher preparation programs). The program coordinator works closely with the GSE official who places the students to make sure that the teachers in the schools chosen for observations practice high quality, student active, inquiry-oriented teaching. To achieve this goal, the preservice teachers are only placed with teachers who either are graduates of the program or work with the program closely. These observations parallel the work in the "Teaching Physical Science" course, which has a set of weekly assignments to foster reflections on classroom observations. Also during this spring semester preservice teachers continue teaching in laboratories and recitations.

In the summer, they enroll in the Research Internship course in X-ray astrophysics. This course accompanies a year-long program for high school students (Rutgers Astrophysics Institute) who learn how to conduct authentic research (in the summer) and then carry out the research (during the following academic year) in x-ray astrophysics (more information about the program can be found in [46]). Preser- vice teachers observe high school students learning physics and astrophysics through the ISLE approach in the summer part of the program and then learn how to access NASA archival databases and interpret photon data to build models of x-ray sources (low and high mass binaries, bursters, supernovae remnants, etc.). This experience allows preservice teachers to not only watch how quickly and efficiently high school students learn when they are in an environment built on knowledge of how people learn, but they also see the "nature of science" at work and learn how to bring real science into the classroom.

In the fall of the second year preservice teachers do their student teaching internship (which is a part of the preparation of all preservice students in the GSE). For this teaching internship they are placed with the cooperating teachers who are graduates of the program (usually these are the same teachers who were observed by the interns in the spring of the previous year). This is both extremely important for the student teaching experience and makes the physics program unique in the GSE. These placements are only possible because of the continuous interaction of the program staff with the graduates (Table III). Placing the interns with the graduates of the program allows the interns to practice what they learned and avoid the conflict between how they are "supposed to teach" and "how real teachers teach." During the student teaching internship, they plan and execute their lessons with the supervision of the cooperating teacher and the university supervisor. Once a week they come to Rutgers for a course, Teaching Internship Seminar, where they reflect on what happened during the week, learn to interpret and assess student work, and plan their new lessons. In the spring, they return to teaching introductory laboratories and recitations at Rutgers. During this semester, they start interviewing for high school teaching positions. The interviews involve teaching a demonstration lesson. These lessons are planned together with the graduate advisor (the author of the paper). Because of these clinical experiences at Rutgers, the preservice teachers slowly build their skills and confidence as they move toward independent teaching. This section provided a general overview of the PCK-related courses; the details of two of them are given in the next section.

\section{RUTGERS PROGRAM COURSE WORK DETAILS}

This section describes two methods courses in detail ("Development of Ideas in Physical Science" and "Teaching Physical Science") and provides an overview of "Multiple Representations in Physical Science." Although a great deal of course work is based on science education literature, the "meat" of the courses is PER-based. During the two years in the program, preservice teachers read and discuss seminal papers of the founders and developers of the PER field (and their corresponding research groups) such as A. Arons, L. McDermott, F. Reif, E. Redish, A. Van Heuvelen, R. Beichner, F. Goldberg, J, Minstrell, D. Hammer, D. Meltzer, and many others. In the Rutgers program these courses are taught in the Graduate School of Education, however all of them can be offered in a physics department, provided that a person in charge is an expert in physics, general pedagogy and 
physics PCK. An important feature of the course content is that the preservice teachers learn how to teach every concept of the high school curriculum at least twice in different courses, from different angles. They also see how those concepts logically build on each other and how to structure the curriculum so students can benefit from those connections.

\section{A. Development of Ideas in physical science (first year, fall semester)}

\section{Overview}

"Development of Ideas in Physical Science" is a threecredit course that meets once a week for $160 \mathrm{~min}$, fifteen times during the semester. The goal of the course is to help students learn how physicists developed the ideas and laws that are a part of the high school physics curriculum. "Ideas" that students investigate correspond to the major building blocks of physics and chemistry, such as motion, force, energy, molecular structure of matter, electric charge, electric current, magnetic field, light as a wave or a photon, and atomic and nuclear structure.

One might question why knowing the history of physics is important for future teachers. There are several answers to this question. One is that knowing the history allows preservice teachers to develop their content knowledge-the knowledge of the inquiry processes through which the discipline develops knowledge. In addition, it might help future teachers develop their PCK. Often student learning resembles scientists' grappling with ideas [47,48]. For example, it took thousands of years for scientists to accept the concept of a rotating Earth. A major obstacle was the concept of relative motion. High school students have a tremendous difficulty with this concept. How might our knowledge of the arguments made by Galileo help us convince our students that one is moving while sitting on a chair in class? Another example is the concept of heat as a flowing material substance. How did scientists come up with this idea and why did they end up abandoning it? What lessons can we learn from their experiences that will help our students understand that heat is not something that resides in the body? These examples by no means suggest that all student learning mirrors the history of science. However, knowledge of this history can be an important tool that strengthens teachers' content knowledge and such aspects of PCK as knowledge of students' ideas and knowledge of curriculum.

In the course, students use the elements of the ISLE cycle (observational experiments, patterns, explanations [hypotheses, relations], predictions, testing experiments ${ }^{2}$ ) as a lens through which they examine the historical process; they learn when this cycle actually worked and when it did not and why. They also examine the sequence in which the ideas

\footnotetext{
${ }^{2}$ Observational experiments are experiments that are used to create models or theories; when doing such experiments a scientist collects data without having a clear expectation of the outcome; testing experiments are the experiments that are used to test (reject) models and theories; while doing such experiments a scientist has clear expectations-predictions-of the outcome based on the model/theory she/he is testing [29].
}

were historically developed and determine which ideas were prerequisites for others. The textbooks used in the course are Refs. [49,50]; however students also read original scientific writings (for example passages from "Two Sciences" by Galileo; Newton's "Principia;" Joule's "Mechanical equivalent of heat;" Faraday's "Experimental researches in electricity") and physics education research papers on student learning of particular concepts. There are three distinct parts in the course.

\section{Details}

Part 1: Individual and group class work. During the first 7 weeks, students work in groups of three to four for about 20-40 min [per activity] on: (a) simple experiments and discussions in which students conduct observations, develop explanations and test them in new experiments (these activities are designed by the course professor and involve modern versions of historical experiments that served as initial puzzling observations or testing experiments for scientists); (b) reading and discussions of the original writings of scientists in which students identify the elements of the reasoning used in concept building by scientists, and reading and discussions of the PER papers that connect historical development of ideas to children's development of the same idea; (c) reflections and discussions of their own learning and comparing their conceptual difficulties to the struggles of scientists. Below we present an example of a class activity that occurs in the very first class of the semester.

Students receive a card with the following information:

"Eratosthenes was the first man to suggest how big Earth is. Here is a summary of the data that he possessed:

(1) The Sun rises and sets in Syene (now Aswan) and Alexandria at the same time.

(2) The Sun lights up the bottoms of deep wells in Syene on the day of summer solstice while the angle that the Sun's rays make with a vertical stick in Alexandria is $7.2^{\circ}$.

(3) It takes a Roman legion between 170 and $171 \mathrm{~h}$ of marching to cover this distance. The average speed of soldiers is $29.5 \mathrm{stadia} / \mathrm{h}$.

Eratosthenes also assumed that Sun's rays striking Alexandria and those striking Syene were parallel."

The students need to use the information on the card to answer the following questions (they work in groups):

(a) On what experimental evidence could Eratosthenes base the assumption about parallel rays? Explain.

(b) How could he explain observations 1 and 2? Draw a picture.

(c) What could Eratosthenes conclude about the shape and the size of the Earth? Draw a picture.

(d) How could he convince others concerning his conclusion?

After preservice teachers answer questions (a)-(d) working in groups, they record their solutions on the white boards and engage in a whole class discussion. This is when they play the role of teachers and discuss the purpose of the activity, the issues of the continuity of knowledge, scaffolding, etc. Here the instructor shares her knowledge of student strengths and difficulties in this activity and the rationale 
behind the questions.

The goal of the activity described above is to contribute to the development of four different aspects of PCK. Of course, one activity cannot fully develop any of those aspects but the intent here is that development will occur through repeated exposure in different contexts over time.

(1) Orientation to teaching. By engaging in this activity as students, preservice teachers experience for the first time (and these experiences will repeat for the next 14 weeks of the semester) how high school students can construct an idea that they knew before as "fact" (how big Earth is) through a learning sequence that is built on processes that actually occurred in the history of science. As one of them commented at the end of class, "I heard in many classes that Eratosthenes measured the size of Earth but never knew how he did it and never thought that students could do the estimation themselves."

(2) Knowledge of curriculum. To answer question (a), preservice teachers need to go back to their knowledge of optics. Why is it important that Sun rays striking Earth are assumed to be parallel? In many of their former physics and astronomy classes, preservice teachers learned to assume that the Sun sends parallel rays of light. But why would we think this, especially when taking into account that all young children draw the Sun sending rays in all directions? Therefore, the goal of the class discussion of this first question is to help them reflect on their own knowledge of optics and to connect it to how children learn and how some ideas are necessary for other ideas to develop. This in turn relates to how one might think of structuring the curriculum.

(3) Knowledge of student ideas. High school students have to struggle with the following issues when responding to questions (b), (c), and (d): the relationship between the locations of two cities on Earth and the times of sunrise and sunset at the locations of the two cities on the surface of Earth (Earth science); the orientation of a well and a stick with respect to Earth's radius (physics); the parallel nature of the sun's rays hitting both cities (physics); the relationship between the angle and the circumference (geometry); proportional reasoning (algebra); unit conversion (algebra and physics). When preservice teachers perform the activity, they face similar issues and struggle with them (mostly with the orientation of a vertical stick and parallel Sun rays). Reflecting on their own progress and what they built on when solving the problem helps them think of what might be difficult for high school students and how they should or should not help. While the physics difficulties of preservice teachers in this example resemble high school students' difficulties, the former are much more skilled in mathematics. Here their instructor helps them see high school student difficulties by explicitly bringing them into the discussion "How do you think high school students will approach the proportional reasoning necessary for this problem? How would you help them set up the proportion? Do they need formal mathematics or can they reason by analogy?"

(4) Knowledge of instructional strategies. After preservice teachers complete the assignments as high school students, they discuss the following questions: Why is there an assumption about parallel rays in the handout? Why is asking students to draw a picture a helpful strategy? Why is it important to teach our students to represent their ideas in multiple ways?

There are multiple pedagogical reasons to do this activity on the first day of class. One is that future teachers start learning to question: "How do we know what we know?" When students study geometrical optics in their general physics courses, they see in books that Sun's rays are drawn parallel, but they rarely question how we know it. Next, the activity shows the preservice teachers the importance of appropriate scaffolding. In the activity above students have to think about several questions before they actually proceed to the calculation of the size of Earth. Removing the assumption about parallel rays from the activity makes it much more difficult and fewer students (I mean preservice teachers here) can complete it. The third reason is that it helps them learn the difference between a hypothesis and a prediction. A hypothesis is a statement explaining some physical phenomenon qualitatively or quantitatively (a synonym to "hypothesis" is "possible explanation"- there can be multiple hypotheses explaining the same phenomenon). A prediction is a statement of the outcome of an experiment based on a particular hypothesis; thus there can be only one prediction for a particular experiment based on the hypothesis under test. These words are used interchangeably in the discourse and even in textbooks. In their course textbook, the students read: "Eratosthenes predicted the size of Earth." However, his calculation was not a prediction, but a "quantitative hypothesis" that needed further testing. Discussions of these subtle differences help preservice teachers later construct their own lessons and design laboratory investigations (for example they ask their students to state which hypothesis they are using to make a prediction for the outcome of a particular experiment).

Part 2: Individual out-of-class work. The second part of the course involves student work with the text "Physics, the Human Adventure" [49] and original writings of the scientists [50]. Each week after a class meeting, students write a report in which they need to describe experimental evidence and the elements of inductive, analogical, and hypotheticodeductive reasoning that contributed to the development of a major "idea" of physics or chemistry using their class notes, the book material, and the original writings. Students need to reconceptualize the material in the book and in the original writings of the scientists in order to identify elements of scientific reasoning: for example, to separate observations from explanations, explanations from predictions, etc. A student sends this report to the course instructor via e-mail, the instructor reads it and provides feedback to the student, who then revises the report based on the feedback. In addition to writing weekly reports related to the material in class readings, students submit a "Popular science report" once a month. They need to find an article in the Science section of the New York Times about some recent development in science (not necessarily physics) and annotate it by identifying the elements of scientific reasoning such as original observations, a question that developed from these observations, proposed hypotheses, testing experiments, applications, etc. 
Part 3: Out-of-class group work and microteaching. At the beginning of the course, students choose an idea (concept) that they will investigate working in groups of two to three for an extended period of time. They have to trace the development of that concept from first observations (if possible) to the stage when it was accepted by other scientists. They also need to prepare a story about one of the persons who participated in the development of the concept. The scientist has to become alive for the listeners-their family, a spouse, personal strengths and weaknesses, friends and enemies-all of the details that make their human are a part of the story.

Preservice teachers also need to design (and teach in class) a high school lesson related to one of the aspects of the concept. The concepts for the projects are: electric charge, electric current, magnetic field, models of light, and atomic and nuclear structure (transformation of elements and fission).

Students, working in groups outside of class, first make an historical outline; then they prepare a lesson that they will teach in class. For example, a group that is working on the history of the development of the concept of magnetic field will teach a lesson in which students develop a concept of magnetic interactions: they observe and devise explanations of the interactions of a compass with a magnet (this activity is similar to the experiments performed by Gilbert), a compass above, below and on the sides of a current-carrying wire (which is similar to Oersted's experiment), and finally design experiments to test their explanations (using an apparatus that has two parallel wires with the current in the same or opposite directions - similar to the experiment conducted by Ampere to test his hypothesis that a current carrying wire is similar to a magnet).

When the preservice teachers start planning their lesson, they tend to focus on the content that they will present instead of thinking about what goals the lesson will achieve. This is where the feedback of the course instructor is invaluable-she helps students think of a lesson as the means to achieve a particular learning goal(s). After the goals are established, the preservice teachers start thinking about how to achieve them. Here again, the main focus of the preservice teachers is what they will do in class as teachers, as opposed to what their students will do to learn. Another difficulty comes later: how will they know that the students learned? What questions will they ask? What possible answers will their students give? The goal of the course instructor is to help preservice teachers think of and plan these aspects of the lesson.

When preservice teachers teach their first few lessons to their fellow preservice teachers, they tend to stick with the plan they devised, without paying attention to the comments and questions of the lesson participants. During the actual teaching, the instructor plays multiple roles: a student who does not understand (to provoke a discussion), a team teacher (to help preservice teachers who are teaching to carry out their plan), and the course instructor, who might interrupt the flow of the lesson and focus the attention of the "teacher" on a student comment that might indicate a difficulty or misunderstanding or a possible need to change the order of the lesson. This latter role becomes more important as the pro- gram progresses since the skill of hearing what students are saying is the most difficult and the most important skill to acquire.

\section{B. Teaching physical science (first year, spring semester)}

\section{Overview}

Teaching Physical Science is a 3-credit course that meets once a week for $160 \mathrm{~min}$. In this course, preservice teachers learn in greater depth and detail how to build student understanding of crucial concepts (velocity, acceleration, force, mass, Newton's laws, circular motion, momentum, energy, electric charge and electric field, potential difference, current and resistance, magnetic field and electromagnetic induction) and of a big picture of physics, how to engage the students in experimental design and complex problem solving, how to motivate them, and how to develop and implement curriculum units and lesson plans, including formative and summative assessments. The focus on listening to high school students and interpreting and explaining what they say and do becomes even stronger. To achieve this goal, preservice teachers practice listening to and interpreting the responses of their peers in class to specific physics questions, read physics education and science education research papers, and conduct clinical interviews with high school or middle school students.

In terms of physics content, the course focuses on mechanics, thermodynamics, electricity, and magnetism in the sequence that is normally used in a high school curriculum, so the preservice teachers see how the concepts should build on each other instead of just being developed as random lessons. The course has the same three components as the "Development of Ideas in Physical Science" (although there are differences in what is taught or what is expected from the preservice teachers) plus there are two additional components. For 10 weeks, students spend $3 \mathrm{~h}$ a day in a high school observing physics lessons and reflecting on their observations (this part was described in the Clinical Practice section). At the end of the semester, they have an oral summative assessment. Notice that some of the physics topics that preservice teachers work with in this course are the same as the ones that they encountered in the Development of Ideas in Physical Science course, but the focus is different. The purpose of using the same content is to have multiple exposures to the same ideas in multiple contexts [31].

\section{Details}

There are several fundamental enduring pedagogical ideas related to teaching physics (PCK ideas) in the course. One of them is the language (verbal, symbolic, etc.) that we use (both instructors and students) and how this language might help or hinder student learning. Another idea that permeates the course is that students learning physics should have "a taste" of what physics is and what physicists do. The focus on the "outcomes"-concepts, equations, laws-often prevents students from seeing the other integral part of physics as a science-its process. In other words, being able to 
explain how one knows something is as important as what one knows. The third idea is that listening to the students and being able to immediately respond during the lesson to students' needs is an important ability, but one that is extremely difficult to master and which needs time and effort to be developed.

Part 1: Individual and group class work. During the first eight weeks of the class, preservice teachers participate as students in ISLE-based physics lessons that mimic high school physics lessons, and they then reflect on their experiences. During these lessons, they work in groups on specific activities that involve: (a) qualitative and quantitative observational experiments, data collection, and analysis and identification of patterns; (b) devising multiple explanations for the observed phenomena and derivations of equations; (c) designing experiments to test their explanations; and (d) designing experiments to determine specific physical quantities. Preservice teachers conduct laboratory experiments that they design (this involves planning data collection and analysis) as opposed to performing cookbook laboratories in which students follow step-by-step instructions on how to set up the experiment, what data to collect, and how to analyze them, and they reflect on the laboratory handout scaffolding questions $[43,44]$. In other words, they experience the process of learning that they will later need to guide their own students to emulate.

As students work on the activities, many issues related to their own conceptual understanding arise despite the fact that they have physics or engineering degrees. In addition, in every course there are a couple of students who are not a part of the physics teacher preparation program but are, for example, middle school science teachers working on a masters degree or mathematics educators taking a course outside of their content area. Participation of those students in class discussions is invaluable as they bring more of a "physics novice" perspective, and make statements or ask questions that resemble, even more than those of the other class participants, the statements and questions of high school students. The instructor's actions when such moments occur are discussed in class from the teacher's point of view.

Class activities that resemble high school physics lessons last for about $2 \mathrm{~h}$ and the third hour is dedicated to the discussions of different teaching strategies, planning, assessment, student difficulties and productive ideas, instructor responses to their questions and comments, etc. Considerable time is dedicated to discussions of why a particular activity is structured in a particular way, what insights specific questions could provide about student learning, and so forth. Many of the class activities come from the Physics Active Learning Guide [ALG, [25,33]]. The learning guide has two editions - student [25] and instructor [33]; the preservice teachers use the student version in class and the instructor edition to complete their homework described below. Another resource used in the classroom is the video website, developed at Rutgers [51]. The website has more than 200

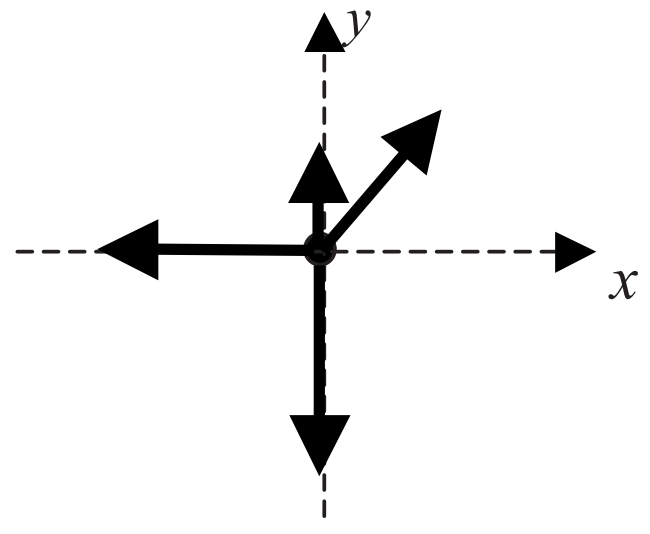

FIG. 3. Unlabeled force diagram.

videotaped physics experiments, many of which can be used for data collection when played frame-by-frame. Using the videos in class allows the students to see many more experiments than would be possible in 14 class meetings if the instructor had to assemble all the equipment; it also allows them to see in slow motion such simple processes as free fall, cart collisions, and projectile motion, or to see weatherdependent electrostatics experiments. Another resource that is used almost every day is the website with simulations developed at CU Boulder [52]. In addition students read and use other curriculum materials.

Below we show a sequence of activities in which preservice teachers engage as students in class no. 3 to learn how to help their students construct the idea of normal force. After performing the activities, they discuss the reasons for that particular order and possible student responses. The sequence is partially based on the research on student difficulties with normal force described in John Clement's paper on bridging analogies and anchoring intuitions [53]. After this class, students read Clement's paper at home and in the next class (no. 4) discuss the reasons for activity structures based on the reading. Finally, they take a quiz that assesses their PCK with respect to normal force. The sequence of student learning of PCK resembles the ISLE cycle-they start with engaging in the learning of a particular concept through a sequence of activities (observations), then devise multiple explanations for the content and structure of the activity, then learn about testing experiments for these different explanations with real students (the testing is described in the physics education research paper), and finally apply these new ideas to solve practical problems (the quiz in class next week).

Class 3 learning activities:

a. Observe and explain: Can a table push?. (a) Perform the experiments described in the first column. Then record your data and fill in the empty cells. Remember that the scale, as a measuring instrument, has an uncertainty of measurement associated with it. 


\begin{tabular}{|c|c|c|c|c|c|}
\hline Experiment & $\begin{array}{l}\text { Draw a picture } \\
\text { of the situation. }\end{array}$ & $\begin{array}{c}\text { List objects } \\
\text { interacting } \\
\text { with the object } \\
\text { of interest. }\end{array}$ & $\begin{array}{l}\text { Draw a } \\
\text { force diagram } \\
\text { for the object. }\end{array}$ & $\begin{array}{l}\text { Discuss what objects } \\
\text { exert forces balancing } \\
\text { the force that } \\
\text { Earth exerts on } \\
\text { the object. } \\
\text { What is (are) } \\
\text { the direction of } \\
\text { the balancing } \\
\text { force (forces)? }\end{array}$ & $\begin{array}{c}\text { Write a } \\
\text { mathematical } \\
\text { expression } \\
\text { for the forces } \\
\text { exerted on the } \\
\text { object. Specify } \\
\text { your axis. }\end{array}$ \\
\hline
\end{tabular}
(a) Hang an object
from a spring
scale. Record the
reading of the
scale here
(b) Lower the object
onto a platform
scale so it touches
the scale.
Record the new
reading of the
spring scale

(c) You place the

object on a tabletop.

Record what happens

(d) You place the

block on the

platform scale and

then tilt the scale at a

small angle.

Record what happens

b. Test an Idea. A book rests on top of a table. Jim says that the force exerted by the table on the book is always the same in magnitude as the force exerted by Earth on the book. Why would Jim say this? Do you agree or disagree with Jim? If you disagree, how can you argue your case?

Class 4 quiz: Notice that the letter $C$ next to the questions below indicates content knowledge. The numbers show the addressed dimensions of PCK (1-orientation to teaching; 2-knowledge of curriculum; 3-knowledge of student prior knowledge and difficulties; 4-knowledge of instructional strategies; 5-knowledge of assessment).

c. Quiz. Your students are learning Newtonian dynamics and are solving the following problem: An unlabeled force diagram for an object on a horizontal table is shown in Fig. 3. Sketch and describe in words a process for which the diagram might represent the forces that other objects exert on an object of interest.

You hear one of the students say: "There is a mistake in the diagram, the upward vertical force should always be the same as the downward arrow."

(1) Do you agree with the student? Explain your answer
$(C)$.

(2) Why do you think the student made this comment? (3)

(3) What activities done in class could have contributed to his opinion? $(3,4,5)$ $3,4)$.

(4) How would you respond to this comment in class? (1,

(5) If you were to test the student's idea, what experiments would you design? $(C, 5)$

d. Individual work outside of class. Every week after a class session preservice teachers read a chapter in "Five Easy Lessons" by Knight [32], as well as reading the side notes (comments for teachers) in the ALG that are related to the class work. They also read the relevant physics education research papers (see the list in Appendix B). They then combine this information with the activities in class; they are told to "write a lesson plan for a lesson that will help your students master concept X. In this lesson plan make sure that you list student ideas related to concept X (use the ALG and "5 Easy Lessons" and the assigned readings) and provide questions that will allow you to assess the progress in student learning of the concept, provide possible student answers and 
examples of your feedback to the student." A template for a lesson plan is shown in Appendix C.

e. Group work outside class and microteaching. Beginning week 4 , preservice teachers, in groups of two, start working on a curriculum unit and a corresponding 2-h lesson that they will teach in class starting week 8 . The curriculum units are: static fluids, kinetic-molecular theory, vibrations, electrostatics, dc circuits, magnetism, and electromagnetic induction. Each unit takes about a month of instruction. The components of a unit that the preservice teachers have to address are: NJ state standards, learning goals, length of the unit, student prior knowledge and potential difficulties, the sequence of lessons (with short outlines), the laboratory (full text of one 2-h laboratory), the final test (full text), the equipment list, and list of resources. Writing a unit is not easy. Table $\mathrm{V}$ provides examples of the difficulties that students encountered in this assignment over the last 6 years and ways in which the instructor provided feedback (both difficulties and the feedback are taken from real unit plans and instructor responses).

In addition to the unit plan, students write a lesson plan for the lesson that they will teach in class. Before writing the unit, the preservice teachers read relevant literature and conduct an interview of a high school student using one of the questions or problems described in a research paper related to the unit. They also investigate other physics curricula and resources: tutorials, interactive demonstrations, workshop physics [54], TIPERs [55], on-line simulations [52,56,57], etc. The structure of the microteaching is the same as for the "Developing Ideas in Physical Science" class.

f. Observations of high school physics lessons (practicum). For these observations preservice teachers are carefully placed in the schools where physics teachers engage students in the construction of their own ideas, in group work and in the development of scientific abilities. In the last two years all of these teachers have been former graduates from the program. When preservice teachers conduct their observations (10 visits, each visit lasts about $3 \mathrm{~h}$ ) they sit in the classroom taking notes, participate as facilitators when students work in groups, coteach several lessons, and informally interview the teachers about the lessons. Each week they write a reflection on their observations answering specific questions (see below); if the questions are not answered satisfactorily, the instructor returns the reflection for improvement. They also determine an RTOP [58] score for one lesson per observation (they learn to use this instrument during the Teaching Physical Science class). During the Teaching Physical Science class meetings there is a short period of time dedicated to discussion of their reflections.

Here are some examples of the questions that preservice teachers answer based on their observations:

Week 1: What were the goals of the lesson and how did the teacher make sure the goals were achieved?

Week 2: How did the teacher start and end the lesson? Did the beginning excite the students? Did the end provide a "hook" for the next lesson or a closure?

Week 3: What forms of formative assessment did the teacher use? What kind of feedback did they provide? How did student performance affect the continuation of the lesson?

Throughout: How did you know that students understood a particular idea or a procedure? Provide 3 examples by quoting what students said or describing what they did and explain how you know that they understood the concept or a procedure.

g. Final examination. The course ends with an oral exam during which preservice teachers need to (a) present in class their thoughts about helping and assessing high school student learning of a particular concept; (b) solve a complex physics problem chosen by the instructor and (c) demonstrate to classmates some exciting physics experiment that they can later use as a "hook" in their own teaching. A month prior to the exam they receive a list of 30 questions related to the teaching of physics that were or will be addressed in the course. For example, "What should your students know about friction? How will they learn it? How will you assess their learning?" During the exam, students are randomly assigned to present answers to two of the questions. The purpose of the exam is to engage preservice teachers in a cooperative preparation of the materials (as it is almost impossible for one person to prepare all 30 questions). Starting two weeks prior to the exam they meet on a regular basis, exchange their ideas, and share responsibilities to prepare the answers. They use the electronic discussion board and hold their own review sessions. Preparation for the exam usually starts the building of a community that will later support the future teachers when they do student teaching, search for jobs, go through the interview process, and later when they leave the program and become teachers.

\section{Multiple representations in physical science (second year, spring semester)}

"Multiple Representations in Physical Science" is a 3 -credit course that meets once a week for $160 \mathrm{~min}$. The physics content covered in the course is: waves and vibrations; thermodynamics and gas laws; electricity and magnetism; geometrical, wave and quantum optics; and atomic physics. The goal of the course is to help preservice teachers integrate different representations of physics knowledge into problem solving. Although preservice teachers have used representations such as motion diagrams, force diagrams, energy bar charts, and ray diagrams in the previous courses, here they learn to approach the representations systematically. Most importantly, they write rubrics for the high school students to help them self-assess their work with different representations. (A rubric is a table with the cells that describe different level of performance for a particular skill; students can use those to check and improve their own work-self-assess themselves, and teachers can use rubrics for grading. An example of a rubric for force diagrams is shown in Table VI. More about rubrics and how to use them see in [43].)

They also investigate opportunities provided by technology to aid students in learning abstract physics ideas. Some 
TABLE V. Preservice teachers' difficulties with a unit plan.

\begin{tabular}{lll}
\hline \hline Unit element & Difficulty & Feedback to the student \\
\hline $\begin{array}{l}\text { NJ state standards } \\
\text { (or National standards) }\end{array}$ & $\begin{array}{l}\text { Preservice teachers focus only on a particular } \\
\text { piece of content (force or energy) and } \\
\text { overlook the standards related to scientific } \\
\text { reasoning, application of mathematics, } \\
\text { technology, etc. }\end{array}$ & $\begin{array}{l}\text { Think of what scientific abilities students should develop } \\
\text { in this unit, what mathematical skills they will develop, } \\
\text { and what applications of technology they will use. Then } \\
\text { match these goals to the standards. }\end{array}$
\end{tabular}

Learning goals

Length of the unit

Student prior knowledge and potential difficulties

The sequence of lessons

2-h laboratory

Final test
Preservice teachers limit the goals to the conceptual goals, missing procedural and epistemological goals and confuse learning goals with the class procedures.

Preservice teachers underestimate the time needed for the students to master a particular concept or ability.

1. Preservice teachers expect the students to know particular things when in fact these very ideas should be developed in the unit that

they are planning.

2. Student difficulties documented in the literature are missing.

3. Students' productive ideas are missing.

1. The lessons are not built on each other; a logical progression is missing.

2. Important ideas are missing which reflect gaps in the content knowledge.

The laboratory in the unit is cookbook.

1. The test problems and assignments do not assess the learning goals of the unit.

2. The test is too long.

3. All problems are difficult.

4. The test consists of multiple-choice questions only.
Think of what other goals you might achieve. Should students learn how to write experimental results as intervals instead of exact numbers? Should students differentiate between a hypothesis and a prediction? How can "students will work in groups" be a goal? Did you mean that students will learn how to work in groups as a team? If yes, then how can you assess this goal?

Think of how long it might take for the students to figure out the relationship between the width of the slit and the distances between diffraction minima. Will they be able to accomplish it in $\frac{1}{2}$ of a lesson?

1. Think of how you can help students learn graphing skills in this unit if they come without this prior knowledge.

2. How can you use R. Beichner's paper to summarize student difficulties with motion graphs?

3. How can you use J. Minstrell's facets to learn what productive ideas students might have about electric current?

1. Will your students understand the minus sign in Faraday's law if they have not yet learned about the direction of the induced current?

2. The idea of coherent wave sources is missing from the unit. Think of how this idea is related to the interference of light.

Think of how you can help students design the experiments instead of providing instructions step by step. Use the examples of design laboratories at: http:// paer.rutgers.edu/scientificabilities.

1. Number the learning goals and then put the numbers corresponding to the goals across each test problem. See which numbers are not addressed and revise the test.

2. Take the test and time yourself. Then multiply this time by 4 or 5 . If you get more than $45 \mathrm{~min}$, the test is too long.

3. Try to maintain a balance of the level of difficulty of the problems so students do not lose confidence during the test.

4. Try to balance between multiple choice and open-ended problems, having about $20 \%$ in m.c. You want to send your students a message that you value their thought process, not only the final answer. 
TABLE V. (Continued.)

\begin{tabular}{lll}
\hline \hline Unit element & Difficulty & Feedback to the student \\
\hline List of resources & $\begin{array}{l}\text { Preservice teachers list the internet sites } \\
\text { and curriculum materials but not physics } \\
\text { books and higher-level textbooks. }\end{array}$ & $\begin{array}{l}\text { What resources related to the depth of the content } \\
\text { did use? }\end{array}$ \\
\hline \hline
\end{tabular}

of the web resources that preservice teachers learn to integrate into their future instruction are the PHET simulations from the University of Colorado [52], Van Heuvelen's ActivPhysics [56], and NetLogo models from Northwestern University [57]. The big emphasis in the course is the connection between the use of multiple representations in physics and our knowledge of how the brain works [60]. In addition to reading research papers relevant to the weekly topics and using the book "Five Easy Lessons" by Knight [32], the students read the book "The Art of Changing the Brain" by Zull [61]; part of the class time is dedicated to discussing the connections between the biology of the brain and the learning of specific topics in physics.

The course has the same structure as the other two courses described above. For the first 6-7 weeks, the professor models problem-solving lessons; the preservice teachers participate as students and then reflect on the lesson. At home, they write a journal in which they describe how they will help students master a particular representation and devise a rubric for self-assessment. After week 7 or 8, they start doing microteaching. This time the lessons focus on problem solving instead of on concept construction (concept construction is the focus in the course "Teaching Physical Science"). At the end of the class, students submit another unit plan and take the oral exam.

\section{DOES THE PROGRAM ACHIEVE ITS GOALS?}

\section{A. Summary of goals}

The program described above has several specific goals. The goals are to prepare a teacher of physics or physical science who: ics,

(i) is knowledgeable in the content and processes of phys-

(ii) can engage students in active learning of physics that resembles scientific inquiry (iii) knows how to listen to the students and assess their learning in ways that improve learning, and

(iv) stays in the teaching profession.

A fifth goal is to increase the number of teachers of physics graduating from the program.

\section{B. What is the evidence that the program achieves these goals?}

\section{Evidence of learning physics content}

For the last 3 years the students have taken FCI [62] and CSEM [63] as pretests when they enroll in the first course in the program. The scores range from very low (40-50\% on FCI to $30-40 \%$ on CSEM) to very high (100\% on FCI and $90 \%$ on CSEM). The preservice teachers who score low are usually those who received their undergraduate degree a long time ago ("postbac" students), have a chemistry major and are pursuing a physical science certification rather than straight physics, have an engineering major, or are students in the five-year program who are taking the bulk of their physics courses in the last year of their undergraduate degree (usually these are transfer students or students who decided to become physics teachers late in the undergraduate course of study). Sometimes those scores can be as low as $25-30 \%$ on FCI. However, after two years in the program preservice teachers make huge improvements in their physics knowledge. The majority score $90-100 \%$ on FCI and $80-90 \%$ on CSEM when they take them in the last course of the program. Another way to assess their level of physics knowledge is to examine the artifacts that the students create while in the program, such as history projects, lesson plans, unit plans, and course assessments; this allows for a much more thorough assessment of preservice teachers' knowledge of the content of physics. As the same instructor teaches all of the PCK courses, these continuous physics-based interactions allow her to assess their current state of knowledge and

TABLE VI. Rubric for assessment of force diagrams [59].

\begin{tabular}{|c|c|c|c|}
\hline Missing & Inadequate & $\begin{array}{l}\text { Needs some } \\
\text { improvement }\end{array}$ & Adequate \\
\hline $\begin{array}{l}\text { No force diagram } \\
\text { is constructed. }\end{array}$ & $\begin{array}{l}\text { Force diagram is constructed but } \\
\text { contains major errors: missing } \\
\text { or extra forces (not matching } \\
\text { with the interacting objects), } \\
\text { incorrect directions of } \\
\text { force arrows or incorrect } \\
\text { relative length } \\
\text { of force arrows. }\end{array}$ & $\begin{array}{l}\text { Force diagram contains no } \\
\text { errors in force arrows but } \\
\text { lacks a key feature such as } \\
\text { labels of forces with } \\
\text { two subscripts or forces } \\
\text { are not drawn from } \\
\text { single point. }\end{array}$ & $\begin{array}{l}\text { The diagram contains all } \\
\text { appropriate force and each } \\
\text { force is labeled so that } \\
\text { one can clearly understand } \\
\text { what each force represents. } \\
\text { Relative lengths of } \\
\text { force arrows are correct. } \\
\text { Axes are shown. }\end{array}$ \\
\hline
\end{tabular}


their progress. This is a subjective part of the assessment as the artifacts are not coded and there is no reliability check; however, the amount of evidence accumulated over the 7 years of the existence of the program allows me to describe some patterns that repeat year after year.

When students come into the program, many of them exhibit the difficulties described in the PER literature, despite the fact that they are completing or have completed a degree in physics or have an equivalent of a physics degree. In addition, their approach to problem solving resembles that of novices-when given a problem they search for equations and when they find the ones that they think are appropriate, they plug in the numbers right away instead of drawing a picture and thinking about relevant concepts, and then deriving the final equation in a symbolic form before plugging in the numbers.

By the end of the program, the graduates become Newtonian thinkers who understand the connections between the net force and the changes of motion of the object; they are also skilled in momentum and energy, electrostatics, DC circuits, and magnetism. In addition, they learn to approach problems in an expert way: represent the problem situation with a picture, a graph, derive an expression for the desired quantity and only then plug in the numbers. These conclusions are based on the quiz performance in the courses in the program and the homework assignments. For example, in the course Teaching Physical Science (TPS, spring of the first year) and in the course "Multiple Representations" (MR, spring of the second year), part of the homework assignment every other week is to solve standard physics problems relevant to the unit (dynamics problems, conservation problems, circuit problems, etc.). In the spring of 2010 in the TPS course on the first assignment for dynamics, of the nine preservice teachers only one person consistently derived the final expression for the answer before plugging in the numbers for all 12 assigned problems. At the same time in the MR course, five out of seven preservice teachers did it (the assignment was for electrostatics and had 13 problems).

Another source of data are the final unit plans and lesson plans. According to the scoring rubric developed for lesson plans adopted by the whole GSE, preservice teachers need to show an understanding of the content through the choice of appropriate NJ standards, goals, prerequisite knowledge, selection of concepts for the lesson and activities for formative assessments. The rubric scores range from 0 to 3 (0-missing; 1-does not meet expectations; 2-meets expectations; 3 -exceeds expectations). Although the reliability in the scoring is not determined as only the course instructor does the scoring, again, multiple years allow us to see some patterns. For example out of 27 first drafts of the lessons that students submitted during the first three weeks of the TPS course in the spring of 2010, 12 were scored 1, 13 were scored as 2 and only 2 were scored as 3 . For the 7 lesson plans submitted at the end of the Teaching Internship seminar (fall 2009, a different cohort) none of them was scored as 1 , three were scored as 2 and another three were scored as 3.

The topic of waves, including wave optics, still presents a challenge even after two years in the program, as does quantum optics and modern physics, as very few students design unit and lesson plans for those topics. The biggest difficulties there are the concepts of coherent waves and the dual nature of photons. The reason is that students encounter the major concepts of mechanics and electricity and magnetism at least three times in different courses in the program in different contexts but they only encounter modern physics and optics once or twice.

Another assessment of graduates' content knowledge comes from their student teaching supervisors and cooperating teachers. For the former, we examined the records of student teachers during the past two years. Each preservice teacher was evaluated 14 times during a semester of student teaching. Because 11 students graduated from the program, there were 154 evaluations available. In each evaluation, among other criteria, the student's demonstrated content knowledge was rated on a scale of $0-3$, where 0 is not observed, 1 is not meeting expectations, 2 is meeting expectations, and 3 is exceeding expectations. Out of the examined evaluations, the majority of the ratings were in the category of 3 (96) with the rest being in the category of 2. Additional data supporting the hypothesis that content knowledge of the graduates is relatively high comes from the interviews of science supervisors of the graduates who are now teaching. They were asked to rate the content knowledge of those of their teachers who are graduates of the Rutgers program. Out of 9 interviewed supervisors (there are 11 graduates teaching in these districts), 6 rated content knowledge of their teachers (Rutgers graduates) to be 10 on the scale of $0-10$ and 3 rated it as 9 .

\section{Evidence of learning physics processes}

Progress in the understanding of the processes of science is achieved similar to the understanding of the content.

Below I describe a part of the study done in the fall of 2003 with the students in the "Development of Ideas in Physical Science." There were ten students in the course working on their MS in Science Education+teacher certification in physics or chemistry. The part of the study described here investigated the following question: Could the students differentiate between different scientific process elements such as observational experiments, explanations, predictions, and testing experiments, and follow the logic of hypotheticodeductive reasoning while reading the book "Physics, the Human Adventure" [49] and reflecting on the classroom experiences?

To answer this question, first submissions of each weekly report were coded with five categories for the instances when students demonstrated: (a) an ability to differentiate between observations and explanations; (b) an ability to differentiate between explanations and predictions; (c) an ability to differentiate between observational and testing experiments; (d) an ability to relate the testing experiment to the prediction; and (e) explicit hypothetical-deductive reasoning (if the hypothesis is correct, and we do such and such, then such and such should happen, but it did not happen therefore we need to revise the hypothesis, examine assumptions, collect more data, etc.). An explanation was a statement related to the patterns in the observed phenomenon, while the prediction involved using an explanation to predict the outcome of a testing experiment. Instances where students confused ele- 
ments in codes (a)-(d) were coded as well. Examples of the statements coded for understanding or confusion for the above categories are shown in Appendix C.

Two raters discussed the codes, then coded student work for one assignment separately, and then discussed the coding again. When their agreement reached $100 \%$ after the discussion, they proceeded scoring the rest of the assignments. The agreement for those without the discussion was around $80 \%$. The results of the coding indicated that, in assignment no. 1, 9 out of 10 students confused observations with explanations; only one did not make this mistake. By assignment no. 8 , none of the students made a mistake confusing an observation with an explanation.

Differentiating between explanations and predictions turned out to be a more difficult task. During the first assignment, only two students attempted to write about predictions and both of them confused these with explanations. In the second week, nine students used these elements and three were successful. The trend continued: in assignment no. 6 of the course, every student was writing about explanations and predictions and 8 out of 10 correctly differentiated between them in most cases. Sometimes, on the same assignment, a student would distinguish between explanations and predictions for one idea and then confuse them for another idea.

Relating predictions to testing experiments was another challenge. During the second week, only two students described what predictions scientists made before performing particular testing experiments. This number increased slightly during the semester, fluctuating between 4 and 9 . One student in the first submission of the reports never mentioned any predictions before describing testing experiments.

\section{Evidence of ability to engage students in active learning of physics}

In the past two years we conducted more than 40 classroom observations of the physics lessons taught by the graduates of the program. During the observations, trained observers collected detailed field notes and determined RTOP [58] scores for the lessons (10 lessons were observed by two observers simultaneously to develop the reliability of the scores). The RTOP (Reformed Teaching Observation Protocol) is an instrument that allows a trained observer to produce a score for a lesson that reflects to what extent the lesson is teacher-centered (teaching process is the focus of the lesson) or student-centered (student learning is the focus of thelesson) [42]. The scale of the instrument is 1-100; a score over $50 \%$ indicates considerable presence of 'reformed teaching' in a lesson. Although it does not directly assess PCK, some RTOP categories reflect it. However for our purpose of assessing the ability to create an interactiveengagement lesson, RTOP is very useful as it allows one to document multiple features of the lesson such as organization of the content, depth of questions, the logic of the lesson, student involvement, teacher attention to students' comment or questions, patience, etc.

The field notes show that the graduates of the program do indeed engage students in active explorations of physical phenomena (found in more than $70 \%$ of the lessons) and group work in which students work together in solving prob- lems and conducting and discussing the experiments (more than $70 \%$ of the lessons). The RTOP scores range from 50 to 87 with the average being 75 . Interviews with the supervisors provided more information about the climate in the classrooms of the graduates. When asked to assign a score to the classrooms of the graduates based on the statement "students are actively engaged in the construction of their knowledge" (score of 1 means not engaged and 10 means very actively engaged), the supervisor rated the classrooms between 8 and 10 ( 2 of them provided a score of 8,4 a score of 9 , and 3 a score of 10 ).

\section{Evidence of graduates' ability to listen to the students and assess their learning in ways that improve learning}

To help teacher candidates achieve this goal in the course that accompanies student teaching "Teaching Internship Seminar" they have the following weekly assignment: every day prior to one of the lessons they will teach, they need to answer the following questions: What do I plan to accomplish? How will I know that students are learning? What are the strengths of the students that I plan to build on? What are potential weaknesses? After the lesson they need to reflect on student learning, providing specific examples of what students said (verbatim) during that lesson that showed evidence of understanding. They answer the questions: What did I accomplish? What did student understanding look like? What were their strengths? What were their weaknesses? What would I change in the lesson now?

This assignment is extremely difficult for the students. During the first 6 weeks of student teaching in 2009 only one student teacher (out of 7 doing student teaching that semester) could consistently show examples of student understanding (most left this part of the assignment blank). As time progressed (and the instructor provided feedback and suggestions), all of the preservice teachers were able to give at least one example of a high school student comment that was indicative of understanding. For example one preservice teacher gave the following example of student understanding:

- Me: "How did you find the acceleration of the sled?"

- Student: "Well, he's pulling the sled at an angle so not all of his force is going into pulling the sled horizontally-so we have to find that portion of the force, which is only this side of the triangle. So we can use the cosine of the angle to find this side, and then use $a$ $=F / m$ to find the acceleration in this direction."

The evidence of the achievement of this goal in those who are already teaching is difficult to obtain, as it requires multiple observations of the same teacher over multiple years. I do not have this evidence. What I have are the notes from field observations of selected teachers, their postings on the discussion board (see below) and their assessment assignments and assessment strategies, which they send to me voluntarily. From the last two sources of evidence I can say that several of the graduates (about 25\%) use student reflective 
TABLE VII. Graduation, teaching and retention data.

\begin{tabular}{llcl}
\hline \hline Year & No. of those who graduated & No. of those who started teaching & No. of those who are still teaching \\
\hline 2003 & 1 (5-year program) & 1 & 1 \\
2004 & 5 (1 5-year program, 4 post-bacc.) & 5 & 5 \\
2005 & 7 (all post-bacc) & 5 & 5 \\
2006 & 6 (1 5-year program, 5 post-bacc.) & 5 & 5 \\
2007 & 5 (all post-bacc.) & 6 & 5 \\
2008 & $6(4$ 5-year program; 3 post bacc.) & 7 & 5 \\
2009 & $7(3$ 5-year program; 4 post bacc.) & \\
2010 & $6(2$ 5-year program; 4 post-bacc.) & \\
\hline \hline
\end{tabular}

journals similar to those they write themselves in the program [64], and many use the system when their students can improve their work on quizzes and get "recovery points" on the tests (about 50\%). A recent development was the invention of one of the teachers (a 2006 graduate) to make students write "a note to yourself going back in time and tell themselves something they would have liked to know at the beginning of the unit." The following is an example of what a high school student wrote after the unit on energy:

"If I could write down one hint to my past self about the energy unit, i (sic) would tell myself to always draw a picture and an energy bar chart. I would give myself this hint, because with a picture I can understand what to look for and what is going on in that scenario. Then with the picture, i (sic) can then know what I had initially and then what I will have in the final state. After this I can create a bar chart. Then once I have my bar chart I know what equations to use and what variable to solve for. I would also hint to make sure that I'm using the correct units and to make sure that I don't have to convert anything to a certain unit. Finally, i (sic) would write down all the units for each kind of variable I have to solve for. In conclusion, I would remind myself to draw a picture, make a bar chart, solve for unknown variable, and check my units."

In the class of this particular teacher $80 \%$ of the students wrote that the note would be either about drawing a bar chart or using a bar chart to set up an equation. The teacher who collected those reflections now used them to help her students prepare for the test. This kind of evidence is not enough to make a claim that all graduates learn how to listen to the students and modify the instruction; much more data are needed here. That is why one of my graduate students is currently working on a dissertation that has a goal of documenting how graduates of the program do this.

\section{Evidence of retention in the physics teaching profession}

Before the program was reformed, the number of graduating students oscillated around two students per year (zero in 1998 , one in 1999, one in 2000, four in 2001, two in 2002) with the retention rate of about $60 \%$.

After the program was reformed, the number of teachers of high school (9-12) physics educated by the program in the past five years and the number of those who remain in the teaching profession oscillates around 6 per year. This is a relatively high number taking into account the very small size of the teacher preparation program at the Rutgers GSE. Table VII shows the number of those who graduated, those who started teaching, and those who remained in teaching.

\section{Collaboration with the physics department}

There are several programs (for example at the University of Arkansas, Illinois State University, and SUNY-Buffalo State College) preparing physics teachers in the U.S. that have features similar to those of the Rutgers Program (multiple course work that focuses on physics PCK, early physics teaching experiences, etc.). What is unique about the Rutgers Program is that it is an Ed. M. program housed entirely in the Graduate School of Education. Two major reasons for such hosting are the NJ certification requirements and the history of teacher preparation at Rutgers. However, the fact that GSE houses the program does not mean that it is the only participant in the process. In fact, it is the collaboration between the Department of Physics and Astronomy and the Graduate School of Education that makes the program successful. Here are several crucial aspects of this collaboration:

(1) The majority of the students in the program (about $60 \%$ ) are Rutgers students (in their senior year) or former Rutgers students. These students receive initial advisement from the Undergraduate director in the physics department. When the undergraduate director in the physics department advising undergraduates senses that a particular student has some interest in pursuing a teaching career, he immediately advises this student to contact the program leader in the GSE; additionally, he himself contacts the GSE coordinator to be on the lookout for this student. He also provides initial advising for the potential teacher candidate.

(2) The Department of Physics and Astronomy provides preservice physics teachers with opportunities to teach in the PER-reformed courses giving them priority over its own graduate students.

(3) Faculty and staff in the physics department are willing to spend extra time providing training for the preservice teachers who are course instructors and holding special sessions on how to use equipment and conduct demonstrations and laboratories. 
(4) The Department of Physics and Astronomy supports the reforms in the introductory courses. These reforms might have had an effect on four students who were not originally physics majors but, after taking one of the reformed courses, became physics majors and entered the physics teacher preparation program.

All of these connections are informal and are based on the good will and commitment to teacher preparation. However, without them the true integration of physics and pedagogy would not be possible.

\section{Creating a professional learning community}

Another important feature of the program is the professional learning community [65] that it attempts to create. It has been found through research on teacher retention that the first three years of teaching are the most difficult and this is when teachers quit most often. In addition, it has been found that if the teacher has the support of colleagues, then the probability of quitting decreases [66]. Based on those findings and the personal experience of the coordinator of the program, who has 13 years of high school physics teaching, one of the goals of the program is to create a learning community that will support new teachers through the most difficult years of their teaching career. The building of the community starts when the preservice teachers are in the program: they interact with each other during project preparation in all courses, during preparation for the oral exams, etc. In addition, they build relationships with the graduates of the program who are now teachers by being their students during the student teaching internship. They also build these relationships by attending the meetings twice a month that are held for the graduates in the GSE. In 2004 the cohort that graduated in 2005 created a web-based discussion group and, since then, all new graduates join this group to stay in touch with each other. Since the fall of 2004 there are on average 70 messages per month (from a low of 15 in the summer to a high of 160 in some months; the number is growing steadily every year) on the discussion list, most of them related to the teaching of specific physics topics, student difficulties and ideas, difficult physics questions, new technology, equipment sharing, interactions with students and parents, and planning of the meetings. When a participant posts a question, a response usually comes within 15-30 $\mathrm{min}$ from another teacher, and then the strand of the discussion goes on for 5-10 exchanges. The average number of participants in the same discussion is 4 with a low of 2 and a high of 8 . The preservice teachers join the group during their student teaching, so that by the time they graduate they are well integrated into the community.

\section{HOW TO GET STARTED?}

The descriptions we have provided of the extensive course work, the student-student and student-instructor interactions in the program, and the follow-up interactions that occur even after the course of study is completed might seem overwhelming. Multiple courses, connections to other departments, complicated clinical practice-all of these ele- ments make the program such a complicated organism that a person reading about it for the first time might think: "I cannot do it, forget it." This is not exactly the message I want to send. One does not have to implement all aspects of the program to achieve similar results. In fact, the program described in this manuscript is changing constantly. The latest change was that the course "Research internship in X-ray astrophysics" became an elective instead of a required course in 2009. There were several reasons for this change. The goals of that course when it was designed were to let preservice teachers observe student-centered, inquiry-based teaching in action with high school students, as well as to learn the nature of authentic research and how to bring some sense of that research into to the classroom. But now, with so many graduates of the program teaching in NJ schools, the current preservice teachers can observe student-centered teaching in real settings. Also, with the new research being conducted in the Rutgers PER group, the preservice teachers take part in research from the beginning of the program. In addition, Rutgers now is interested in preservice teachers teaching physics courses for incoming freshman in the summer. Due to all of the above reasons, the research internship course became an elective (although most of the teacher candidates enroll in it). The reason I describe this change is to show that the program is a living organism that changes in response to outside conditions. What is important is that the philosophical aspects stay the same. Several of them can be adopted by a physics department committed to physics teacher preparation and can help students who plan to become physics teachers:

(1) Learn physics through the pedagogy that preservice teachers need to use when they become teachers. This can be done in a general physics course reformed according to active-engagement strategies in which students experience learning physics as a process of knowledge construction. The important issue here is the reflection on the methods that are used in the course and the discussion of the reasons for using these methods in the context of the most important concepts and relationships learned in the course.

(2) Learn how the processes of scientific inquiry work and how to use this inquiry in a high school classroom for specific physics topics. This can be done by engaging students in the learning of physics through experimental explorations, theory building, and testing, and making specific assignments where students need to reflect on how their own construction of the concept compares to the historical development of the same physics concept. In addition, preservice physics teachers can engage in undergraduate research experiences with subsequent reflection on how scientists work.

(3) Learn what students bring into a physics classroom and where their strengths and weaknesses are. This can be done through reflection on the preservice teachers' own learning of specific concepts and mathematical relationships while they themselves are enrolled in a general physics course; they can read and discuss papers on student learning of particular concepts. Later, when they do student teaching, they can focus on analyzing responses given by students who are learning the same concepts.

(4) Engage in scaffolded teaching in reformed courses before doing student teaching or starting independent teaching. This can be done through a program similar to ones that 
employ Learning Assistants, or by giving seniors an opportunity to teach laboratory and recitation sections with training, feedback, and reflection.

(5) Learn how to plan and assess instruction. This can be done through an additional course offered in parallel to the teaching experiences. This course can be team taught by an expert in physics and an expert in education, or by an expert in physics education research and a "teacher-in-residence" (a "teacher-in-residence is an experienced teacher who takes off a year from high school teaching to work at a university science department on course reforms, preservice teacher education, outreach programs, etc.).

(6) Form a learning community. This can be done by creating an on-line tool for the students to communicate while they are in the program so they can continue conversations after graduation. A faculty member can contribute to the discussions, but even without these contributions the graduates will be able to support each other.

(7) Be prepared for a long time needed for learning. Just as physicists need multiple courses over an extended time interval to learn physics, our students need multiple courses over an extended time interval to learn how to become physics teachers. Do not expect immediate changes after one activity or one course. My experience is that a great deal of time and effort are needed before you will see changes in your preservice teachers.

\section{SUMMARY}

The program described in the paper has been in place for eight years. During this time we observed a growth in the number of teacher graduates, a high level of retention, and an increase in the number of Rutgers physics majors coming into the program. The unique features of the program are the strong and continuous emphasis on physics pedagogical knowledge, ample opportunities for the students to practice newly acquired knowledge, and the presence of a supportive community. Students in the program enroll in six physicsspecific teaching methods courses. All of these courses model the instructional practices that 21 st century teachers are expected to implement. The assessment of the teaching practices of the graduates shows that they do implement the knowledge and skills acquired in the program. The program attracts students despite the high cost and with no external funding support.

\section{ACKNOWLEDGMENTS}

I am grateful to my colleagues in the Graduate school of Education who supported the change in the physics teacher preparation program; to the Department of Physics and Astronomy that helps recruit students for the program and provides them with opportunities for clinical practice, my graduate student Tara Bartiromo who helped organize and edit this paper; Allison Parker, Danielle Bugge, Chris D'Amato, and Jessica Watkins who helped collect data, and Amy Wollock and Alan Van Heuvelen for their comments and suggestions on the paper. I also want to express special thanks to Robert Beichner, David Meltzer, Peter Shaffer, and three anonymous reviewers who helped revise and improve the paper.

\section{APPENDIX A}

Multiple paths that lead to becoming a physics teacher through Rutgers. Diagram 1 shows multiple paths to becoming a teacher.

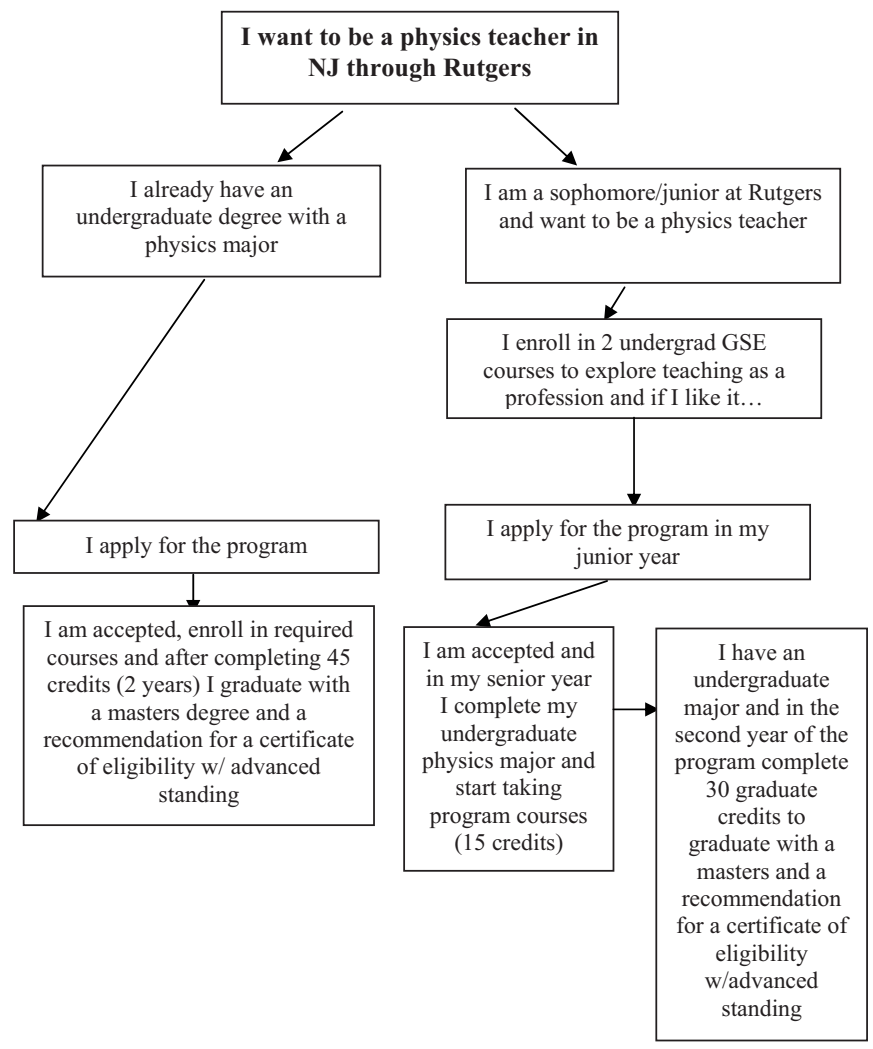

In the 5-year physics program, students who are undergraduate physics majors begin taking courses in the school of education in their fourth year of undergraduate studies. The courses that they take in the GSE do not apply to their undergraduate major which they complete by the end of their fourth year (independently of being admitted into the GSE program). However, they do apply to the required number of credits needed to earn the bachelor's degree. Then, after they receive their $\mathrm{BS}$ or $\mathrm{BA}$ degree in physics, they continue the program in the fifth year. In the postbaccalaureate program, students already have undergraduate physics or engineering degrees. The total number of credits (semester hours) that 5-year students take in the GSE is 52 (only 30 credits taken in the fifth year are at the graduate level) and for postbaccalaureate students it is 45 .

\section{APPENDIX B}

Part 1: Weekly reading assignments for the "Teaching Physical Science" class (in addition to reading a chapter from "5 Easy Lessons" by R. Knight and a chapter from the "Physics Active Learning Guide" by A. Van Heuvelen and E. Etkina)

For class 2 
P. Kraus and J. Minstrell, Designing diagnostic assessments, Proceedings of 2002 PERC conference, Franklin, S., Cummings, K. and Marx, J., Eds. PERC Publishing. (2002)

D. Hammer, Two approaches to learning physics, The Physics Teacher, 27, 664 (1989).

A. Elby, Helping physics students learn how to learn, American Journal of Physics, 69, 54 (2001).

N. Nguyen and D. Meltzer, Initial understanding of vector concepts among students in introductory physics courses, American Journal of Physics 71(6), 628-638 (2003).

For class 3

R. J. Beichner, Testing student interpretation of kinematics graphs, American Journal of Physics 62(8), 750-762 (1994).

E. Etkina, A. Van Heuvelen, S. White-Brahmia, D. T. Brookes, M. Gentile, M., S. Murthy, D. Rosengrant, and A. Warren, Scientific abilities and their assessment, Physical Review Special Topics: Physics Education Research. 2, 020103 (2006).

For class 4

D. Hestenes,, M.Wells, and G. Swackhamer, Force concept inventory, The Physics Teacher, 30, 159-166 (1992).

L. McDermott, Research on conceptual understanding in mechanics, Physics Today, 14, 24-30 (1984).

For class 5

J. Minstrell, Explaining "the rest" condition of an object, The Physics Teacher, 1(1), 10-15 (1982).

J. Clement, Using Bridging analogies and Anchoring intuitions to deal with students' preconceptions in physics, Journal of Research in Science Teaching, 30(10), 1241-1257 (1993).

For class 6

A. Van Heuvelen, Learning to think like a physicist: A review of research-based instructional strategies, American Journal of Physics, 59(10), 891-897 (1991).

A. Van Heuvelen and X. Zou, Multiple representations of work-energy processes, American Journal of Physics, 69(2), 184-194 (2001).

For class 8

C.H. Kautz, P. R. L. Heron, M. Loverude, and L. McDermott, Student Understanding of the Ideal Gas Law, Part I: A macroscopic perspective, American Journal of Physics, 73(11), 1055-1063 (2005).

C.H. Kautz, P. R. L. Heron, P.S. Shaffer, and L. McDermott, Student Understanding of the Ideal Gas Law, Part II: A microscopic perspective, American Journal of Physics, 73(11), 1064-1071 (2005).

For class 9
M. Loverude, C.H. Kautz, and P. R. L. Heron, Helping students develop an understanding of Archimedes' Principle. I. Research on student understanding, American Journal of Physics, 71(11), 1178-1187 (2003).

P. R. L. Heron, M. E. Loverude, P.S. Shaffer, and L. McDermott, Helping students develop an understanding of Archimedes' Principle. II. Development of Research-based instructional materials, American Journal of Physics, 71(11), 1187-1195 (2003).

For class 10

D. Maclsaac and K. Falconer, Reforming physics instruction via RTOP, The Physics Teacher, 40, 479-485 (2002).

For class 11

D. Hammer, Two approaches to learning physics, The Physics Teacher, 27, 664-670 (1989).

For class 12

M. Vondracek, Teaching Physics with math to weak math students, The Physics Teacher, 37, 32-33 (1999).

(1) Title

(2) NJ standards addressed in the lesson.

(3) What students need to know before they start the lesson.

(4) Goals of the lesson, e.g., conceptual (what ideas or concepts will students construct during the lesson), quantitative (what mathematical relationships they will master), procedural (what skills they will learn and practice), and epistemological (what they will learn about the nature of knowledge and the process of its construction).

(5) Most important ideas subject matter ideas relevant to this lesson-describe in detail. Real life connections (make a list).

(6) Student potential difficulties (what might cause trouble) and resources (what you can build on).

(7) Equipment needed, group it into teacher use and student use.

(8) Lesson description: a script of the lesson (What is going to happen, what you will say, what questions you will ask, what students will do, all handouts that you plan to give to the students). Choose activities that are best for the content of the lesson. Make sure you describe how you will start the lesson and how you will end it (to capture students' attention and to have some sort of closure).

(9) Time Table — who is going to be doing what and when during the lesson to make sure that students are actively engaged.
Clock reading during the lesson
"Title of the activity"
Students doing
Me doing

$0-6 \min$

Homework quiz

Writing

Checking up equipment for the first activity

(10) All formative assessments that you plan to use and how you will provide feedback (e.g., if these are problems-include solutions).

(11) Modification for different learners

(a) Compensatory activities for those students who lack prerequisite knowledge.

(b) Describe alternative instructional strategies for diverse learners such as the use of multi-sensory teaching approaches, use of instructional technologies, advance organizers, and cooperative learning activities. 
(c) Describe modifications for bilingual students.

(d) List opportunities for students to speculate on stereotypes that exist within the field (in this example-the physical sciences).

(12) Homework-make sure that it addresses two goals: strengthens this lesson and prepares students for the next lesson. Describe the guidance that you will provide to the students.

\section{APPENDIX C}

Examples of student writing coded for specific categories

Coding category

(a) an ability to differentiate between

observations and explanations

(b) an ability to differentiate between explanations and predictions;

(c) an ability to differentiate between observational and testing experiments

(d) an ability to relate the testing e xperiment to the prediction;

(e) explicit hypothetico-deductive reasoning (if, and, then, but or and, therefore)

Evidence of confusion

Evidence of understanding

Galileo observed that when objects were dropped from a higher elevation they left a deeper impression in the sand (pile driver).

Mayer explained that the difference between $\mathrm{C}_{\mathrm{p}}$ and $\mathrm{C}_{\mathrm{v}}$ for gases was due to the additional work that needs to be done on the gas when it expands at constant pressure.

Joseph Black observed that the heat needed to warm up the same mass by the same number of degrees was much less for quicksilver than for water. He found this surprising as quicksilver was denser than water.

Galileo predicted that the distance that the ball rolling down an inclined plane will increase as $1,3,5$ units for each successive unit of time. The prediction was based on the idea that objects fall at constant acceleration and the assumption that rolling down the plane is similar to falling.

Ampere reasoned that if two currents behave like magnets and he placed them next to each other, then they should repel when the currents are in the opposite direction and attract when are in the same directions.
Galileo observed object falling at constant acceleration

Mayer predicted the difference between $\mathrm{C}_{\mathrm{p}}$ and $\mathrm{C}_{\mathrm{v}}$ because of the work done.

Joseph Black was testing quicksilver and water for the amount of heat they need to change the temperature by 1 degree.

Galileo predicted that the balls would roll down at the same acceleration.

\section{APPENDIX D: COURSE WORK}

See separate auxiliary material for the course syllabi, examples of class assignments, and student work.

[1] National Research Council, National Science Education Standards (National Academy Press, Washington, D.C., 1996).

[2] National Commission on Mathematics and Science Teaching for the 21st Century. Before It's Too Late (National Academy Press, Washington, D.C., 2000).

[3] L. S. Shulman, Knowledge and Teaching: Foundations of the New Reform, Harv. Educ. Rev. 57, 1 (1987).

[4] American Association for the Advancement of Science, Blueprints for Reform; Science, Mathematics and Technology Edu- cation: Project 2061 (Oxford University Press, New York, 1998).

[5] L. C. McDermott, Millikan Lecture 1990: What we teach and what is learned-Closing the gap, Am. J. Phys. 59, 301 (1991).

[6] L. C. McDermott, A perspective on teacher preparation in physics and other sciences: The need for special science courses for teachers, Am. J. Phys. 58, 734 (1990).

[7] J. H. van Driel, N. Verloop, and W. de Vos, Developing science teachers pedagogical content knowledge, J. Res. Sci. Teach. 
35, 673 (1998).

[8] J. H van Driel, D. Beijaard, N. Verloop, Professional Development and Reform in Science Education: The Role of Teachers' Practical Knowledge, J. Res. Sci. Teach. 38, 137 (2001).

[9] L. S. Shulman, in Handbook of Research on Teaching, 3rd ed., edited by M. C. Witrock (Macmillan, New York, NY, 1986).

[10] E. Etkina, Physics teacher preparation: Dreams and reality, Journal of Physics Teacher Education online 3, 3 (2005).

[11] P. L. Grossman, What are we talking about anyhow: Subject matter knowledge for secondary English teachers, in Advances in Research on Teaching, Vol. 2: Subject Matter Knowledge, edited by J. Brophy (JAI Press, Greenwich, CT, 1991), pp. 245-264.

[12] S. Magnusson, J. Krajcik, and H. Borko, in Examining pedagogical content knowledge: The construct and its implications for science education, edited by J. Gess-Newsome and N. G. Lederman (Kluwer Academic Publishers, Dordrecht, 1999), pp. 95-133.

[13] D. L. Ball, The Mathematical Understandings That Prospective Teachers Bring to Teacher Education, Elem. Sch. J. 90, 449 (1990).

[14] H. Borko and R. T. Putnam, in Professional development in education: New paradigms and practices, edited by T. R. Guskey and M. Huberman (Teachers College, Columbia University, NY, 1995), pp. 35-66.

[15] J. Brophy and J. Alleman, Activities as Instructional Tools: A Framework for Analysis and Evaluation, Educ. Res. 20, 9 (1991).

[16] P. L. Grossman, The Making of a Teacher: Teacher Knowledge and Teacher Education (Teachers College Press, New York, 1990).

[17] J. Gess-Newsome and N. G. Lederman, Examining Pedagogical Content Knowledge (Kluwer Academic Publishers, Boston, 2001).

[18] J. Loughran, P. Mulhall, and A. Berry, In search of Pedagogical Content Knowledge in science: Developing ways of articulating and documenting professional practice, J. Res. Sci. Teach. 41, 370 (2004).

[19] Onno de Jong, Jan H. Van Driel, and N. Verloop, Preservice teachers' Pedagogical Content Knowledge of using particle models in teaching chemistry, J. Res. Sci. Teach. 42, 947 (2005)

[20] J. Loughran, A. Berry, and P. Mulhall, Understanding and Developing Science Teacher Pedagogical Content Knowledge (Sense Publishers, Rotterdam, Taipei, 2006).

[21] P. Grossman, A. Schoenfeld, and C. Lee, in Preparing Teachers for a Changing World, edited by L. Darling-Hammond and J. Bransford (Jossey-Bass, San Francisco, CA, 2005), pp. 201231.

[22] J. Minstrell, in Designing for Science: Implications for Professional, Instructional, and Everyday Science, edited by $\mathrm{K}$. Crowley, C. D. Schunn, and T. Okada, Mahwah, NJ, 2001), p. 369.

[23] A. Van Heuvelen, Learning to think like a physicist: A review of research-based instructional strategies, Am. J. Phys. 59, 891 (1991)

[24] F. Reif and J. I. Heller, Knowledge structure and problem solving in physics, Educ. Psychol. 17, 102 (1982).

[25] A. Van Heuvelen and E. Etkina, Active Learning Guide (Addison Wesley, San Francisco, CA, 2005).
[26] D. T. Brookes, The Role of Language in Learning Physics, Unpublished Doctoral dissertation, Rutgers University, 2006.

[27] D. Gentner and D. R. Gentner, in Mental Models, edited by D. Gentner and A. L. Stevens (Erlbaum Associates, Hillsdale, N.J., 1983).

[28] A. Van Heuvelen and D. P. Maloney, Playing Physics Jeopardy, Am. J. Phys. 67, 252 (1999).

[29] E. Etkina and A. Van Heuvelen, Investigative Science Learning Environment-A Science Process Approach to Learning Physics, edited by E. F. Redish and P. Cooney, Research Based Reform of University Physics, (AAPT), (2007). Online at http://per-central.org/per_reviews/media/volume1/ISLE2007.pdf

[30] S. S. Stodolsky and P. L. Grossman, The Impact of Subject Matter on Curricular Activity: An Analysis of Five Academic Subjects, Am. Educ. Res. J. 32, 227 (1995).

[31] A. Arons, Teaching Introductory Physics (Wiley, New York, 1997).

[32] R. Knight, Five easy lessons (Addison Wesley Longman, San Francisco, CA, 2003).

[33] A. Van Heuvelen and E. Etkina, Active Learning Guide. Instructor edition (Addison Wesley, San Francisco, CA, 2005).

[34] R. Clift and P. Brady, in Studying Teacher Education: The Report of the AERA Panel on Research and Teacher Education, edited by M. Cochran-Smith and K. Zeichner (Lawrence Erlbaum, Mahwah, NJ, 2005), pp. 309-424.

[35] V. Otero, N. Finkelstein, R. McCray, and S. Pollock, Who Is Responsible for Preparing Science Teachers? Science 313, 445 (2006). For more information on the University of Colorado at Boulder program, see http://stem.colorado.edu.

[36] A. Collins, J. S. Brown, and S. E. Newman, in Knowing, Learning, and Instruction: Essays in Honor of Robert Glaser, edited by L. B. Resnick (LEA, Hillsdale, NJ, 1989), pp. 453494.

[37] B. J. Reiser, Scaffolding complex learning: The mechanisms of structuring and problematizing student work, J. Learn. Sci. 13, 273 (2004).

[38] D. Wood, J. S. Bruner, and G. Ross, The role of tutoring in problem solving, J. Child Psychol. Psychiatry 17, 89 (1976).

[39] A. Collins, J. S. Brown, and A. Holum, Cognitive apprenticeship: Making thinking visible, Am. Educ. 15, (1991).

[40] National Research Council, in How People Learn, edited by J. D. Bransford, A. L. Brown, and R. R. Cocking (National Academy Press, Washington, D.C., 1999).

[41] Tomorrow's Teachers: A Report of The Holmes Group (Holmes Group Inc., East Lancing, Michigan, 1986).

[42] R. R. Hake, Interactive-Engagement Versus Traditional Methods: A Six-Thousand-Student Survey of Mechanics Test Data for Introductory Physics Courses, Am. J. Phys. 66, 64 (1998).

[43] E. Etkina, A. Van Heuvelen, S. White-Brahmia, D. T. Brookes, M. Gentile, M. S. Murthy, D. Rosengrant, and A. Warren, Developing and assessing student scientific abilities, Phys. Rev. ST Phys. Educ. Res. 2, 020103 (2006).

[44] E. Etkina, S. Murthy, and X. Zou, Using introductory labs to engage students in experimental design, Am. J. Phys. 74, 979 (2006).

[45] NJ state standards http://www.edusite.com/nj/science/cccs.htm

[46] E. Etkina, T. Matilsky, and M. Lawrence, What can we learn from pushing to the edge? Rutgers Astrophysics Institute motivates talented high school students, J. Res. Sci. Teach. 40, 
958 (2003).

[47] D. T. Brookes and E. Etkina, Using conceptual metaphor and functional grammar to explore how language used in physics affects student learning, Phys. Rev. ST Phys. Educ. Res. 3, 010105 (2007).

[48] D. T. Brookes and E. Etkina, Force, ontology and language, Phys. Rev. ST Phys. Educ. Res. 5, 010110 (2009).

[49] G. Holton and S. Brush, Physics, The Human Adventure (Rutgers University Press, New Brunswick, NJ 2001).

[50] M. Shamos, Great Experiments in Physics (Dover Publications, New York, 1987).

[51] http://paer.rutgers.edu/pt3

[52] http://phet.colorado.edu

[53] J. Clement, Using bridging analogies and anchoring intuitions to deal with students' preconceptions in physics, J. Res. Sci. Teach. 30, 1241 (1993).

[54] The Physics Suite. A series of curriculum materials including Interactive Tutorials (M. Wittmann, R. Steinberg, and E. Redish), Interactive Lecture Demonstrations (D. Sokoloff, and R. Thornton), Real Time Physics (D. Sokoloff, R. Thornton, and P. Laws) and Workshop Physics (P. Laws) (Wiley, Hoboken, NJ, 2004).

[55] C. J. Hieggelke and D. P. Maloney, T. L. O'Kuma, Steve Kanim. E \& M TIPERs: Electricity and Magnetism Tasks (Prentice Hall, Upper Saddle River, NJ, 2006).

[56] ActivPhysics by A. Van Heuvelen http://wps.aw.com/ aw_young_physics_11/0,8076,898588nav_and_content,00.html

[57] http://ccl.northwestern.edu/netlogo/

[58] D. Sawada, M. Piburn, K. Falconer, R. Benford, and I. Bloom, Reformed Teaching Observation Protocol: Reference Manual, ACEPT Technical Report \#IN00-3 Arizona Collaborative for
Excellence in the Preparation of Teachers, 2000.

[59] See rubrics at http://paer.rutgers.edu/scientificabilities

[60] Cognitive theories such as perceptual symbol systems propose that human thinking happens in the perceptual areas of the brain. The more perceptual areas of the brain are associated with the concept the more the concept is understood and the easier it is accesses/retrieved. One can find more information on the subject in L. W. Barsalou, Perceptual symbol systems, Behav. Brain Sci. 22, 577 (1999) However, this paper is not a part of class reading due to its complexity.

[61] J. Zull, The Art of Changing the Brain: Enriching the Practice of Teaching by Exploring the Biology of Learning (Stylus Publishing, Sterling, Virginia, 2003).

[62] D. Hestenes, M. Wells, and G. Swackhamer, Force concept inventory, Phys. Teach. 30, 141 (1992).

[63] D. P. Maloney, T. O'Kuma, C. Hieggelke, and A. Van Heuvelen, Surveying students' conceptual knowledge of electricity and magnetism, Am. J. Phys. 69, 12 (2001).

[64] E. Etkina, Weekly Reports: A two-way feedback tool, Sci. Educ. 84, 594 (2000).

[65] A learning community is a group of people who share values and beliefs about a particular subject and continuously learn together from each other. For some references about the attributes of the community, see D. W. McMillan and D. M. Chavis, Sense of community: A definition and theory, Am. J. Community Psychol. 14, 6 (1986); and P. Freire, Teachers as Cultural Workers: Letters to those who Dare to Teach (Westview Press, Boulder, Colorado, 1998).

[66] L. Darling-Hammond, The challenge of staffing our schools, Educational Leadership 58, 12 (2001). 